Revista de Dialectología y Tradiciones Populares, vol. LXXIII, n. ${ }^{\circ}$ 2, pp. 295-324, julio-diciembre 2018,

ISSN: 0034-7981, eISSN: 1988-8457,

https://doi.org/10.3989/rdtp.2018.02.002

\title{
CARTOGRAFÍAS
}

\section{La antropología de los contextos musulmanes desde España: inmigración, islamización e islamofobia}

\author{
The Anthropology of Muslim Contexts from a Spanish \\ Perspective: Immigration, Islamization and Islamophobia
}

\author{
Virtudes Téllez Delgado ${ }^{1}$ \\ Universidad de Castilla-La Mancha \\ Ángeles Ramírez Fernández ${ }^{2}$ \\ Universidad Autónoma de Madrid
}

\section{RESUMEN}

Los orígenes de la antropología del islam han estado vinculados a un cierto cuestionamiento epistemológico de la producción de arabistas y orientalistas, de quienes la antropología buscaba distinguirse, con el fin de evitar la reificación del islam y la esencialización de grandes áreas y poblaciones sobre una supuesta base religiosa. Frente al orientalismo, las etnografías priorizaban el conocimiento de la gente y sorteaban los esencialismos. Sin embargo, el fundamento teórico de la antropología del islam ha identificado un objeto, el islam, que en ciertos sentidos reproduce algunas de las perspectivas que tanto se han criticado al arabismo, aunque al mismo tiempo contengan reflexiones fundamentales para nuestro quehacer como antropólogas. Esta cartografía hace un recorrido por las aportaciones de la antropología de los contextos musulmanes en el panorama académico del Estado español, tratando de reconstruir la racionalidad de temas y de enfoques, así como de identificar regularidades, con el objeto de ofrecer una hoja de ruta para orientarse por la enorme producción existente; y de proponer algunos debates que sitúen a la antropología en un lugar no solo académico, sino de producción de discursos públicos crítica y políticamente construidos.

Palabras clave: Antropología del islam y de los contextos musulmanes; Orientalismo; Musulmanes; Musulmanas; Islamofobia.

\section{SUMMARY}

The origins of the anthropology of Islam have been linked to an epistemological reconsidera-

\footnotetext{
${ }^{1}$ Correo electrónico: virtudes.tellez@uclm.es. ORCID iD: <https://orcid.org/0000-0002-7293-6946>.

${ }^{2}$ Correo electrónico: angeles.ramirez@uam.es. ORCID iD: <https://orcid.org/0000-0002-8825-9361>.
} 
tion of the work of Arabists and Orientalists-which anthropology has sought to differentiate-in order to prevent the reification of Islam and the essentialisation of large areas and groups of people on an alleged religious basis. Ethnographies prioritised understanding the people and dodged essentialisms, but the theoretical framework of the anthropology of Islam identifies an objectIslam-which in certain respects reproduces some of the perspectives for which Arabism has been criticised, while at the same time containing fundamental reflections for the job of the anthropologist. This cartography provides an overview of the contributions from the anthropology of Muslim contexts from the academic perspective of the Spanish state in an attempt to reconstruct the reasoning behind different topics and approaches and to identify regularities. The aim is to offer a roadmap to navigate the enormous amount of existing work and to propose debates that situate anthropology in a space that is not only academic, but also related to the production of critically- and politically-constructed public discourses.

Keywords: Anthropology of Islam and Muslim Contexts; Orientalism; Muslims; Islamophobia.

\section{INTRODUCCIÓN}

Aunque pueda parecer chocante, la presentación de una cartografía sobre la antropología de los contextos musulmanes ${ }^{3}$ elaborada desde España, ha de comenzar con una crítica a los estudios clásicos del islam y a la construcción de este espacio disciplinar, siendo conscientes de que, como relatoras de este estado de la cuestión y como antropólogas de este ámbito, no superamos los principales dilemas a los que nos conduce este cuestionamiento.

Los estudios sobre las comunidades musulmanas en Europa no se han podido separar de los lugares de origen de esta población; al mismo tiempo, antropólogas y antropólogos españoles, o europeos, que trabajan en el norte de África, en algún momento han terminado abordando también cuestiones que tienen que ver con diferentes aspectos de la inmigración magrebí (o viceversa). A modo de marchamo de autenticidad, sucede como si para escribir sobre islam en Europa pareciera lo más conveniente trabajar con la teoría generada en los contextos arabo-musulmanes (más específicamente que musulmanes) y tener, o haber tenido, algún contacto etnográfico en/con ellos. Así, la inmensa mayoría de las y los autores que escriben sobre islam en Europa, tienen como horizonte teórico lo que se escribió sobre estos contextos arabo-musulmanes. Por ejemplo, hay correspondencia y continuidad conceptual entre lo que Saba Mahmood (2004) escribe sobre mujeres que comienzan a aprender Corán en las mezquitas cairotas y a usarlo para su vida cotidiana, con el trabajo de Rouse (2004) en relación a las afroamericanas conversas al islam y las negociaciones en su vida diaria en Estados Unidos. Se trata, en los dos casos, de mujeres musulma-

\footnotetext{
${ }^{3}$ Nos referimos a una antropología de los contextos musulmanes, en lugar de antropología del islam, porque como se explica a lo largo de la cartografía, esta última ha estado sujeta a un esencialismo histórico relacionado con sus orígenes orientalistas. Con esta nueva denominación tenemos un doble fin. Por un lado, pretendemos desbordar los límites geográficos con los que se ha vinculado el islam (principalmente la zona de los países árabes). Por otro lado, buscamos incidir en la necesidad de observar las prácticas concretas de las personas que se autodefinen como musulmanas, que están sujetas a la agencia de estas personas y no a unos territorios concretos; a su religiosidad, reivindicaciones y rol social y político y no a la religión entendida como un ente exterior a la gente. Sin embargo, a los propósitos de esta cartografía, cuando nos estemos refiriendo a autores clásicos que emplearon esa terminología, utilizaremos antropología del islam.
} 
nas en situaciones sociales, políticas y económicas bien diversas, pero inmersas en procesos que son naturalizados como si fueran comparables, justamente por la religión que - supuestamente- comparten. Al mismo tiempo, este tipo de estudios se hacen hegemónicos también como horizonte teórico en los trabajos que se realizan entre musulmanas en Europa, en la idea de que se van a encontrar temáticas similares. Desde la etnografía se hace difícil pensar esta traslación de contextos, idea basada en un reificación de la cultura, al modo en que se concebía al inicio de la disciplina. En estas lógicas esencialistas se da el riesgo de hablar del islam y de las gentes musulmanas como una especie de núcleo cerrado sobre sí mismo, que no varía esté donde esté y que mantiene una coherencia interna y una cohesión. Es decir, todo lo contrario a lo que hacemos desde la etnografía. Por eso, uno de los mayores problemas al elaborar este trabajo ha sido la delimitación de su objeto, algo que quizás carezca de sentido si se está hablando de cualquier otro ámbito.

Todo esto es lo que deseamos desarrollar en esta cartografía. Para ello, presentaremos el dilema teórico que encierran las producciones académicas de esta línea de investigación, mostraremos los recorridos temáticos realizados desde los años 90 del siglo XX hasta la fecha (décadas de desarrollo del área) y reflexionaremos sobre la intersección entre las realidades sociales contemporáneas y los enfoques de estudio. Veremos cómo la asociación entre islam, musulmanas, musulmanes y migración ha guiado al campo desde su construcción, tal y como mostrarán las distintas publicaciones referidas en la cartografía, donde la preocupación por los vínculos coloniales, la migración, su gestión, la religión, la islamofobia y las incursiones en el Magreb, marcarán las líneas de debate y reflexión en el desarrollo del campo de estudio. En esta evolución, la academia francesa tendrá un gran peso en sus orígenes, observándose una actual incipiente atención hacia la anglosajona, que podría explicarse en parte por la ineludible hegemonía del inglés. A pesar de estas influencias, podemos afirmar que la antropología del islam y de los contextos musulmanes tiene una idiosincrasia propia en el Estado español, marcada por la proximidad con Marruecos y por la configuración histórica de vínculos hispano-marroquíes, complementarios al alto porcentaje de población musulmana en las ciudades autónomas de Ceuta y Melilla y a una afectación propia por las distintas lógicas de violencia global ${ }^{4}$ que guían y preocupan las reflexiones en el presente.

El origen de este trabajo es el encargo que nos hizo la RDTP para la sección de temas emergentes, en la que nosotras propusimos el título: "Islamofobia y nuevos pánicos morales". Contactamos entonces con colegas que aceptaron participar en el monográfico. El Comité editorial de la revista decidió después convertir el formato en una "Cartografía", ante el temor de que lo que entonces era un tema emergente, no lo fuera después, cuando saliera el número - algo que desgraciadamente no se ha cumplido, siguiendo la estela de los mismos procesos en otros países europeos-. Pero justamente un tema emergente se caracteriza por su novedad en el panorama académico, de modo que difícilmente se podría llevar a cabo una cartografía de un tema que recién comenzaba. Por todo esto, ha resultado complicada la materialización de la cartografía que hemos elaborado, y nos ha ocupado mucho más espacio del que habíamos previsto inicialmente. El resultado final ha acabado centrándose en

\footnotetext{
${ }^{4} \mathrm{Al}$ referirnos aquí a la violencia global, no solo estamos pensando en el llamado terrorismo yihadista sino, también, a las formas de violencia estructural y política que, de un modo institucional estatal y global son ejercidas igualmente sobre las personas musulmanas.
} 
una antropología de los contextos musulmanes/antropología del islam, que para nosotras reubica disciplinarmente los estudios de islamofobia, objeto primario de aquel encargo, y que traza una línea que va desde la antropología colonial en Marruecos hasta la antropología de las comunidades musulmanas en España.

El criterio tenido en cuenta para la inclusión de las obras es que estuvieran etnográficamente fundamentadas, y/o que sus autoras y autores se adscribieran a grupos de investigación o a departamentos de Antropología. Pero hay muchas disciplinas presentes en esta cartografía, porque la antropología de los contextos musulmanes se ha construido en relación con otras: el arabismo, la historia, las ciencias políticas o la sociologías. Puede observarse una focalización de las autorías en Madrid y Cataluña, lo que se debe a que la mayor parte de las autoras y los autores se encuentran en la Universidad Autónoma de Madrid, Universitat Autònoma de Barcelona, Universidad Complutense de Madrid y Universitat de Barcelona, así como que el mayor volumen de población marroquí se encuentra en Cataluña y en tercer lugar en Madrid, después de Andalucía ${ }^{6}$, el otro foco de producción científica destacado en la cartografía. Pero también puede deberse a nuestro propio y nunca suficientemente reflexionado centralismo académico.

Para su elaboración nos ayudaron los repositorios, como Dialnet y muchos otros, pero el hilo está marcado por nuestras propias experiencias como antropólogas y nuestra percepción de las temáticas y preocupaciones de la disciplina. Hemos optado por incluir monografías, más que artículos, cuando ha habido esa posibilidad. Desgraciadamente, la presión para publicar artículos, propia de esta universidad neoliberal, que cae fundamentalmente sobre las personas más jóvenes, hace que se elija estratégicamente escribir textos cortos para ser publicados como artículos en revistas JCR y que se haya perdido la posibilidad de disponer de libros, que era un formato más habitual en la antropología en España. En ese sentido, aunque a veces la cartografía pueda tener la apariencia de un catálogo, por la enorme cantidad de referencias, es un trabajo impresionista como apuntaba otra cartografía anterior (López, Mariano y Medina 2016). Impresionista es siempre subjetivo y personal. Y aquí, como en el resto de la vida, lo personal es político.

\section{LA ANTROPOLOGÍA DE LA CUESTIÓN MUSULMANA ${ }^{7}$ EN ESPAÑA: LA TENSIÓN EN- TRE EL ORIENTALISMO Y LA CONSTRUCCIÓN DE UN ÁMBITO DISCIPLINAR}

No es posible empezar una revisión sobre antropología de los contextos musulmanes sin tomar en consideración las relaciones de la disciplina con el orientalismo.

\footnotetext{
${ }^{5}$ Los enfoques securitarios recientemente desarrollados en relación a la radicalización, concepción y abordaje del llamado terrorismo yihadista no han sido tenidos en cuenta, puesto que más que enriquecer nuestro campo, son uno de nuestros objetos de crítica por el modo esencialista e islamófobo en que se están desarrollando.

${ }^{6}$ Los últimos datos demográficos del Observatorio andalusí (2018) permiten apreciar la distribución de los musulmanes y las musulmanas en la extensión del Estado español. El mayor número se encuentra en Cataluña (522 113), luego en Andalucía (314 980) y después en Madrid (285 993).

${ }^{7}$ Utilizamos esta expresión parafraseando a Vincent Geisser (2012) quien la acuñó en su artículo "La "question musulmane" en France au prisme des sciences sociales", publicado en Cabiers d'Études Africaines 206-207: 351-366.
} 
No es el momento de elaborar aquí una crítica a Edward Said (2003 [1978]), que le sobran, pero sí de enfatizar nuestra idea de que naturalmente, no toda la producción orientalista en todo momento entra en las categorías de las representaciones coloniales e imperiales que Europa usó para justificar la dominación, tal y como reza el argumento central del autor, sobre todo sostenido por sus exégetas, que no fueron contradichos por Said.

En 1981, Gellner, tan endiosado en la antropología en general, como denostado en la antropología del islam en particular (Asad 1986; Varisco 2005), relataba la siguiente conversación:

Los orientalistas están a sus anchas entre los textos. Los antropólogos están a sus anchas en las aldeas. La consecuencia natural es que aquéllos tienden a ver el Islam desde arriba, éstos desde abajo. Recuerdo a un antropólogo, especialista en un país musulmán, quien me contaba de su primer encuentro con un anciano y distinguido islamicista. El viejo erudito comentó que el Corán se interpretaba de manera diferente en diversos lugares del mundo musulmán. El joven antropólogo señaló que ello era obvio. ¿Obvio? ¿Obvio? replicó airado el anciano-: ¡tardé años de paciente investigación en averiguarlo! (Gellner 1986 [1981]: 142).

Este texto representó durante mucho tiempo una manera de hacer de la antropología, diferente a la del arabismo y de los estudios de orientalismo. Antropólogas y antropólogos salían triunfantes de esta contienda, con sus ideas sobre la gente de verdad, con sus métodos que captaban y explicaban los contextos locales, más allá de libros y discursos que pertenecen a las élites y a la Gran Tradición. Pero orientalismo es un término que nos persigue a las que trabajamos con contextos y temáticas musulmanas (Cardeira 2016) y del que no conseguimos mantenernos a salvo. Porque por un lado, haciendo etnografía (Herzfeld 1997), desmontamos el esencialismo del viejo orientalista, que pensaba que todos los musulmanes eran iguales solo por serlo; por otro y al mismo tiempo, haciendo esa misma etnografía cuando hacemos antropología del islam, lo actualizamos y revitalizamos, puesto que tenemos un objeto, el islam, al que podemos acceder con legitimidad en todos sus aspectos. En estos tiempos en los que las investigadoras e investigadores del área somos constantemente requeridas desde espacios mediáticos o políticos —no necesariamente institucionalesel dilema es aún mayor. Como antropólogas, respondemos a la estigmatización con un discurso crítico y basado en la etnografía; como orientalistas ${ }^{8}$, nos encontramos presionadas para tomar posición sobre todas las temáticas que afecten a cualquier cosa relacionada con el islam y con la población musulmana, con la dificultad añadida de tener que bregar con unos conceptos que están dotados de un cariz fuertemente estigmatizado y securitizado.

Pero, ¿qué es una antropología del islam? Con Asad (1986), tenemos que seguir diciendo que no es fácil delimitarla; si el islam no es una categoría analítica, no puede existir tal antropología. En la historia de la disciplina, los adjetivos que han ido acompañando a la antropología del islam han ido cambiando, en parte también por las variaciones idiomáticas. Según Eickelman (1989 [1981]), Middle East o mundo arabo-

\footnotetext{
${ }^{8}$ Por orientalistas nos referimos aquí, no a reproductoras del orientalismo, tal y como lo definió Edward W. Said, sino a investigadoras de las temáticas que son herederas de las tratadas por el Orientalismo.
} 
musulmán en castellano se utiliza para definir la zona que va de Rabat hasta Teherán, que nace en el siglo XIX como un término de estrategas militares, como un concepto "desvergonzadamente eurocéntrico". La zona que delimita coincide con la primera ola de invasiones árabes y, más o menos, con los tres grandes imperios del Mediterráneo desde la conquista árabe: el omeya, el abasí y el otomano. El hecho de que estos países fueran islamizados a la vez, permitió a muchas autoras y autores, desde diferentes perspectivas, analizar el impacto del islam en la misma época en sociedades próximas geográficamente. Durante décadas y hasta el día de hoy, se siguen editando manuales o compilaciones del tipo Women in Middle Eastern History, que por cierto, fue pionero en su género, de las antropólogas Nikki Keddie y Beth Baron (1991). Naturalmente, el espíritu de estas obras no es la consideración del Middle East como un área cultural en el sentido clásico de que hay factores o rasgos que le dan unidad a la zona. Sin embargo, el hecho es que nos encontramos que los trabajos sobre, por ejemplo, Qatar y Marruecos, comparten manual y a veces, hasta autora.

A esta cuestión se añade otro dato interesante para los argumentos que sostenemos en esta cartografía. Hasta la edición de 1998 del manual de Eickelman (hay dos anteriores, en 1981 y en 1989), Middle East aparece incluyendo los países árabes mas Turquía, Irán, Afganistán y Pakistán, que es —si excluimos este último- lo que en castellano venimos llamando mundo arabo-musulmán. Pero en la edición de 1998 aparece ya el Asia Central, que está conformada por lo que fueron las repúblicas de la URSS ${ }^{9}$, independizadas en nuevos Estados a lo largo de la década de los 90. Eickelman (1989 [1981]: viii) justificó la inclusión de estos países refiriéndose al hecho de que desde los últimos años ochenta, comenzaron a tener lugar una serie de intercambios comerciales y culturales que antes no había, además de una intensificación de la cooperación entre colegas rusos y del Asia Central, por un lado, y europeos y americanos, por otro. Obviamente, más allá de las cuestiones políticas, que fuerzan decisiones disciplinares, no hay argumento teórico para estos cambios.

Aún tendría más recorrido el texto de Eickelman con respecto a la delimitación del ámbito disciplinar. Cuando la editorial Bellaterra tradujo el manual de Eickelman en 2003 y solicitó un prólogo de una de las autoras de este artículo, tuvimos un largo debate concerniente al título que llevaría en castellano. A pesar de que la propuesta de la prologuista era justamente titularlo como Antropología del mundo arabomusulmán y Asia Central o de los contextos musulmanes, finalmente se optó por Antropología del mundo islámico, con lo cual se terminaba poniendo la religión en primer lugar, acabando con cualquier pretensión de considerar otros factores más allá del islam en conformación de este espacio teórico.

La historia del manual de Eickelman, en definitiva, muestra esta tensión - compartida por la mayor parte de las antropólogas y antropólogos que trabajamos en este ámbito- entre la negación de la existencia de ese área para la antropología, al mismo tiempo que se asume como un ámbito disciplinar discreto. No se ha resuelto esta cuestión. El manual más recientemente publicado sobre la materia es el del antropólogo John Bowen, en 2012, que lleva como título A New Anthropology of Islam. En él se refiere a las ideas y los textos religiosos, tal y como son entendidos y transmitidos en diferentes momentos y lugares a lo largo y ancho del mundo musulmán y ahora

\footnotetext{
${ }^{9}$ Son Azerbaiyán, Turkmenistán, Uzbekistán, Tayikistán, Kazajstán y Kirguizistán.
} 
sí, también entre la población musulmana procedente de la inmigración que reside en Europa.

\section{ANTROPOLOGÍA DE LAS MIGRACIONES MAGREBÍES}

Al contrario de lo que ocurre en Francia, donde los intelectuales y científicos sociales estuvieron muy implicados en la dominación colonial de los siglos XIX y XX en el norte de África, inscribiéndose también el análisis de la cuestión musulmana en esta genealogía, el compromiso en España con la producción científica colonial sobre Marruecos fue mucho menor. Por un lado, los arabistas españoles continuaron con el análisis del oriente doméstico, como lo denomina López García (2016), centrados en los estudios sobre Al Andalus. Por otro lado, será el momento de la emergencia de los intelectuales y militares africanistas que desde el siglo XIX y de diversas maneras apoyaban el colonialismo español en Marruecos y compartían un compromiso científico o simplemente erudito por este país. Ellos, que debieron ser llamados marroquinólogos, serán los que producirán las primeras obras en las que las lenguas marroquíes, el tamazigh o beréber y el dariya o árabe marroquí, con sus diferentes variantes, tendrán un importante papel (Hernando de Larramendi y Azaola 2006). En España no hay una producción sobre el Magreb comparable a la francesa (Mateo Dieste 2002), pero hay que rescatar la paraetnografía y la etnografía realizada desde la administración colonial, como la de Blanco Izaga ${ }^{10}$, Benítez Cantero o García Figueras (López y Mateo 2005).

Tan solo hay una excepción antropológica en este panorama, que es la obra de Caro Baroja, con su extensísima monografía sobre el Sáhara occidental, producto de una estancia de tres meses en 1953, en la que trabajó codo con codo con militares, así como su (breve) recopilación de artículos sobre el norte de Marruecos (Caro Baroja 1957 y 1990). No hubo sin embargo conformación de equipo por parte de Caro Baroja que recogiera el testigo de su erudición antropológica o de su incipiente especialización en el mundo arabo-musulmán. Pudo ser por su periférico lugar académico, pero seguramente tuvieron más peso las individualistas y jerárquicas relaciones intelectuales de la época, que impedían una concepción más colaborativa de la formación.

Por su parte, los estudios sobre contextos musulmanes o sobre migraciones procedentes del norte de África no ocupan un lugar hegemónico en la antropología española, que tradicionalmente ha preferido otras áreas, como América Latina, o ha llevado a cabo una antropología hecha en casa por obligación, mientras el territorio del Estado constituía un entorno amigable de trabajo de campo para la potente y colonialista antropología anglosajona (Moreno Navarro 1975).

Sin duda, la primera antropología de los contextos musulmanes en España viene de la mano de las migraciones marroquíes y argelina, desde mediados de los años ochenta. Ahí se van a encontrar antropólogas y antropólogos trabajando en equipos que abordan las migraciones del norte de África, a veces no como tema principal. Hay que mencionar en este sentido el papel pionero de Carlos Giménez en el estu-

${ }^{10}$ La edición más reciente, con un material gráfico muy interesante, sobre la obra de Blanco Izaga se debe al documentalista Moga Romero (2009). 
dio de las nuevas agriculturas capitalistas en el litoral mediterráneo y la inserción de los trabajadores extranjeros, especialmente magrebíes y subsaharianos, en este sector (Giménez 1991 y 1994). La idea de estas primeras etnografías es mostrar la ligazón entre la inmigración del norte y del Sahel africanos y el desarrollo de una agricultura fuertemente competitiva que necesitaba una mano de obra precaria y estigmatizada para poder existir. Algunas de estas zonas se convierten en áreas preferidas de estudio por estas nuevas generaciones de antropólogas y antropólogos, como el País Valencià (Jabardo 1993; Zapata 1993) o el Maresme catalán (Ramírez 1992 y 1993). Pero los estudios sobre antropología de los contextos musulmanes en España le deben justamente su razón de ser, no a un antropólogo, sino a un historiador, arabista de formación, un orientalista, que de hecho es el director de esos primeros proyectos de investigación sobre migraciones magrebíes, Bernabé López García. El hecho de que el área de estudio de este autor fuera fundamentalmente Marruecos, modela también el perfil investigador probablemente de la totalidad de científicas y científicos sociales que se forman en las universidades españolas desde los últimos años de los ochenta. Las ciencias políticas, estudios árabes, sociología, historia y, por supuesto, antropología, son los campos disciplinares de los que salen especialistas que a su vez desarrollarán líneas propias de investigación en universidades de todo el Estado, a partir de la relación con lo que será uno de los primeros grupos de investigación en la universidad española, el Taller de Estudios Internacionales Mediterráneos de la Universidad Autónoma de Madrid, liderado por López García, que comienza su andadura en 1991 y que aún hoy continúa en activo. La Revista de Estudios Internacionales Mediterráneos (REIM), un producto académico del grupo de investigación, es referencia hasta el día de hoy en los estudios sobre la materia.

Los atlas de la inmigración magrebí en España, coordinados por López, Planet y Ramírez (1996 y 2004) y basados en parte sobre un análisis de materiales estadísticos inéditos en aquel momento, sobre migraciones magrebíes, aglutinan una serie de trabajos de algunas antropólogas que si bien más adelante diversifican sus líneas de investigación, constituyen aproximaciones etnográficas novedosas a un proceso del que se conocía muy poco. Es el caso de Gregorio (1996), quien además elabora con Ramírez un ensayo que trata de comparar procesos migratorios de las inmigrantes marroquíes y caribeñas (Gregorio y Ramírez 2000) y de Franzé (1996). Esta última fue además coeditora, junto con la arabista Laura Mijares, de una obra pionera sobre el impacto de los programas de enseñanza de lengua y origen (ELCO) aplicado al alumnado marroquí en la escuela española. Más tarde, Franzé publicaría una extensa etnografía sobre educación e inmigración (Franzé 2002), indagando en el impacto del papel adjudicado a la "cultura de origen" por parte de la institución escolar sobre la trayectoria escolar de hijas e hijos de inmigrantes — con especial énfasis en la inmigración marroquí- y sobre las construcciones o representaciones de la integración. En suma, un análisis de cuán larga podría ser "la sombra del origen", según Franzé (Franzé y Mijares 1999). En una línea similar, Mijares (2006) llevó a cabo una etnografía en la que analizaba el papel de la escuela en el proceso de aprendizaje de la marroquinidad por parte de hijas e hijos de inmigrantes marroquíes, a través de las estigmatizadas representaciones que tenía el profesorado y la institución en general. Los geógrafos también se ocupan de la temática migratoria magrebí, destacando el estudio de Pumares (1996) y el de SempereSouvannavong (1998), este centrado en las migraciones de descolonización. 
Otros trabajos de la época se ocupan de las difíciles condiciones de vida de la ya no tan nueva inmigración marroquí en España a partir del análisis de la segregación urbana y del racismo, como el de Martínez Veiga (1999), que además realiza uno de los dos trabajos que han tratado el racismo antimagrebí (2001). Un estudio relevante es el de Martín Díaz (2002a), que lleva a cabo una evaluación del estallido racista unos años después. El caso de El Ejido ${ }^{11}$ hizo que se multiplicara el interés por el racismo en España, especialmente el producido contra la población árabe, pero no abrió ninguna línea específica de estudios ${ }^{12}$, aunque era un tema central en las etnografías realizadas en el área, especialmente por Martín Díaz (Martín y Rodríguez 1999; Martín Díaz 2002b). No se usaba sin embargo el término islamofobia en aquel momento y el racismo se construía desde una perspectiva marxista, como un instrumento para la explotación de la población obrera marroquí. Aquí hay alguna analogía - muchos años después- con los primeros análisis franceses franco-magrebíes. También Talha (Talha et al. 1983) o Baroudi (1978) construyen esta aproximación marxista a las migraciones magrebíes, en la que el racismo aparece firmemente anclado en las relaciones de producción. En el panorama español, esos tiempos pre-Al Qaeda y pre-Daesh, muestran que no hacía falta la amenaza terrorista para construir el pánico moral. El islam apenas existía en las etnografías, más allá de una referencia religiosa abstracta y de algunos trabajos que se analizan más abajo.

\section{LA ISLAMIZACIÓN DE LA INMIGRACIÓN Y LA (SIEMPRE) EMERGENTE ANTROPO- LOGÍA DEL MAGREB}

La inmigración procedente del norte de África se va difuminando como lugar etnográfico, y si en el momento analizado más arriba la producción antropológica es diversa y vinculada a diferentes líneas dentro de la antropología, termina siendo un reducto prácticamente de esas antropólogas y antropólogos de los contextos musulmanes. Efectivamente, es a últimos de la década de los 90 cuando una entonces joven generación conforma disciplinarmente ese ámbito y lleva a cabo etnografías tanto en los países musulmanes como en otros contextos islámicos de lo que algunos autores han nombrado como diáspora. En este sentido, cabe destacar dos etnografías centradas en las mujeres marroquíes, la de Ramírez (1998), que construye su objeto en las relaciones entre el islam y el género en las migraciones, y la de Aixelà (2000), sobre parentesco y género en Marruecos. Aquí el islam se sitúa no ya como el elemento que explicaba todo, tal y como le decía el orientalista al antropólogo en el texto de Gellner, sino que se rescata el islam vivido, el islam práctico ${ }^{13}$, como parte

${ }^{11}$ En el año 2000, dos agricultores ejidenses habían sido asesinados por un hombre marroquí; unas semanas después una mujer también ejidense, de 26 años, fue asesinada a manos de un hombre con una enfermedad mental, dándose la circunstancia de que el asesino era marroquí. Este último asesinato provocó una suerte de Noche los cristales rotos en El Ejido, donde los vecinos arrasaron y destruyeron tiendas marroquíes, centros de culto y quemaron vehículos.

${ }^{12}$ Los estallidos racistas se hicieron sentir también en antropología. El antropólogo Mikel Azurmendi (2001), presidente del Foro para la integración social de los inmigrantes, órgano consultivo del gobierno de la nación, publicó un texto en 2001 que levantó acusaciones de las antropólogas y antropólogos del Estado español por su carácter marcadamente racista.

${ }_{13}$ Parafraseamos aquí el título de la monografía de Cardeira (1999). 
fundamental de la vida social de las mujeres marroquíes. Sin pertenecer al panorama académico español, hay que mencionar dos obras de gran relevancia en la conformación del campo de estudio. Una es la de Maria Cardeira (1999), que realizó una etnografía clásica en un contexto que también lo había sido para la antropología del Magreb, la medina de Salé, esta vez desde la concepción del islam práctico de las mujeres urbanas de clases populares. La segunda es la etnografía de Rosander (2004 [1991]) sobre las mujeres ceutíes de origen marroquí y la conformación de las concepciones de género a lo largo de la vida en un lugar de frontera ${ }^{14}$. Estas cuatro etnografías enfocan de un modo rupturista las cuestiones de género, parentesco e islam, cuestionando la idea base de una ciencia social liberal que pretendía salvar a las mujeres -especialmente a las árabes y musulmanas- de una cultura opresora (Cardeira 2008; Abu-Lughod 2013) y en definitiva, de los propios hombres de su cultura. En estos trabajos, la negociación con el patriarcado y la normalización de las vidas cotidianas de las mujeres se inspira fuertemente en los trabajos de Hildred Geertz (1978), invisibilizados por la extensa producción de su esposo en la época, pero con un enfoque mucho menos exotizante y esencialista que él en lo que se refiere a este ámbito. Hay que sumar una quinta etnografía, la realizada por Hernández Corrochano (2008), que, en una línea similar a las anteriores, destaca el papel del parentesco y la gestión femenina de este en un entorno urbano cambiante. Por otra parte, desde el arabismo, hemos podido disponer desde muy temprano de una buena base documental sobre género y marcos jurídicos, como los trabajos de Ruiz de Almodóvar-Sel (2005) y también de Pérez Beltrán (1997), que desde la dirección de la Cátedra Emilio García Gómez, que asume en 2004, ha conformado una importante línea académica sobre contextos musulmanes que ha permitido decenas de reuniones, foros y congresos de especialistas, con apoyo específico a publicaciones. Especial atención merecen los trabajos de la arabista Gema Martín Muñoz sobre temas muy diversos. Para lo que aquí nos ocupa, hay que mencionar la recopilación de 1995 sobre mujeres, derechos y democracia en el Magreb y en la inmigración, obra pionera en su género y que además rescató y difundió para la academia española una serie de nombres de autoras que eran absolutamente desconocidas en el panorama español.

Si se exceptúan los trabajos de la politóloga de formación arabista, Ana Planet (1997 y 1998), del sociólogo Joan Lacomba (1996, 1998, 1999a y 1999b) o del antropólogo Jordi Moreras, que firma las etnografías pioneras sobre musulmanes en España (1999), no hay apenas trabajos específicos sobre el islam con un enfoque de ciencias sociales hasta los años 2000. Son estos autores los que desde un momento más temprano comienzan a utilizar los términos de islam y musulmanes en sus investigaciones, en las que el papel de los marroquíes es protagonista en el primer caso, coprotagonista con senegaleses en la Comunidad Valenciana en el segundo y con pakistaníes en Barcelona en el tercero. Planet (2014) realizó una investigación sobre el comportamiento electoral en las comunidades musulmanas de Melilla y Ceuta, rompiendo el estereotipo de los perfiles políticos de la población musulmana, siendo después referencia para los procesos de institucionalización del islam en España. Lacomba tuvo un peso muy importante en este ámbito de estudios a comienzos de siglo con sus

${ }^{14}$ La etnografía de Rosander fue traducida al castellano más de 10 años después de su publicación original en inglés. 
dos publicaciones sobre la figura de los imames inmigrados (2000 y 2001a) y las transformaciones y adaptaciones de las prácticas culturales y religiosas de marroquíes en suelo español, a lo que se refirió como "el islam inmigrado" (2001b). Moreras sería el protagonista de una cartografía del estudio de los musulmanes y el islam en Cataluña, a partir de la etnografía. Sus aportaciones son numerosas y citamos aquí una parte de ellas, como el estudio de los procesos de integración del colectivo marroquí en Cataluña (2001a, 2001b, 2002a, 2002b y 2003a) y las particularidades del pakistaní (2005a); la observancia de las distintas formas de visibilización del islam en el espacio público (2003b, 2003c, 2008, 2014, 2016 y 2017a; Alonso et al. 2015); el rol de los imames en Cataluña (2007); la integración de los colectivos musulmanes en España en clave de sospecha (2005b) y más recientemente como agentes de radicalización (2012, 2015 y 2017b). La reflexión que ha lanzado recientemente al contexto europeo cuestiona las formas en que las personas musulmanas son concebidas en las políticas y muchos trabajos académicos en la actualidad europea, donde aparecen representados por un proceso de extranjerización asociado a un pasado migratorio (2017c). Su propuesta es la de iniciar el campo de la antropología del islam postmigratorio en el espacio europeo. Por último, hay que señalar la extensa producción del antropólogo Ignacio Castien, que a caballo entre la psicología y la antropología, explora la construcción de las identidades en diferentes poblaciones musulmanas, comenzando con la inmigración marroquí en Madrid (2003) y continuando con sus trabajos sobre Senegal (2016), Afganistán (2015a), el Sáhara Occidental (2015b), Mauritania (2014) y, por supuesto, Marruecos (Morales y Castien 2014).

Los atentados del 11S irrumpen social, política y académicamente en 2001 provocando un giro ontológico en la concepción de los sujetos de estudio, quienes dejarán de ser nombrados marroquies para pasar a ser referidos mayoritariamente como musulmanas y musulmanes, creando un efecto que se ha nombrado como la islamización de la migración (Allievi 2006; Mijares y Ramírez 2008a). Este giro se irá consolidando tres años después, con los inesperados atentados del 11M en Madrid. En este sentido, la identificación de la hasta ahora población marroquí como musulmana es, entre otras cuestiones, un efecto de las políticas de gestión del islam, que eligen nombrar por la religión a unos interlocutores de los que se espera actúen como contención frente a lo que después se conocerá como procesos de radicalización de los musulmanes. Para una persona musulmana, el único modo de tener un espacio ciudadano será a partir de la etiqueta religiosa. Esta cuestión reorientaliza y esencializa aún más el ámbito de esta cartografía. La islamización de la literatura se corresponde con un énfasis en una suerte de proceso de reislamización de las poblaciones musulmanas, que habría comenzado en los años 90 y que fue primeramente elaborado en la literatura francesa en esta década (Roy 1992 y 2011; Khosrokhavar 1997; Kepel 2011). Esta interpretación está fuertemente cuestionada por otros autores (Geisser 2016), ya que reduce toda la lógica social de poblaciones procedentes de países musulmanes, a una racionalidad islámica, idea que fundamentará después cierto discurso racista que relaciona la religión con el terrorismo.

La política internacional de Guerra contra el terror ya está asentada a principios de siglo y se abrirán tres líneas principales de investigación en respuesta a la misma: las reacciones de las personas musulmanas a este contexto de sospecha; el estudio de las dinámicas de ciertas religiosidades islámicas identificadas como sospechosas y 
por último, el análisis de las formas de vigilancia y control ejercidas sobre ellas por su relación con la denominada islamofobia. De un modo paralelo a esta nueva deriva que protagoniza las reflexiones de esta última década, se mantendrán las investigaciones que venían realizándose en el campo de las migraciones y en el Magreb. En ambas derivas, la juventud, la infancia y las mujeres tendrán un espacio propio desde el que reflexionar sobre sus dinámicas y el significado o sentido de sus prácticas. Cataluña y Madrid serán los núcleos principales de producción científica, acompañados por los trabajos realizados en Andalucía y el País Valencià. Los focos de análisis tendrán tres espacios geográficos privilegiados como referencia: Marruecos, el Mediterráneo y España, con miradas más minoritarias hacia Mauritania (López Bargados 2006a y 2012; López Bargados y Ojeda 2009), el Sáhara (tanto los campamentos de personas refugiadas en la provincia argelina de Tindouf como el Sahara occidental) y Senegal.

En cualquier caso, Marruecos seguirá siendo el lugar etnográfico más importante en esta antropología de los contextos musulmanes del siglo XXI, visto desde diferentes perspectivas. La antropología y la historia se combinan en el trabajo de uno de los antropólogos más prolíficos del área, Josep Lluís Mateo Dieste, que desde una original perspectiva historiográfica en la que combina el trabajo de archivos con la etnografía más clásica ${ }^{15}$, busca comprender el pasado del Protectorado español en Marruecos, en cuanto al desarrollo de un sentimiento de hermandad hispano-marroquí (2003) con sus tensiones y conflictos (2012), conversiones religiosas (2013), lógicas de corrupción entre colonizados y colonizadores (2014), el establecimiento de matrimonios mixtos (2005) o los sistemas de clasificación social en relación al poder militar en el contexto colonial (2002). Los dos polos de la antropología de esta cartografía, los contextos musulmanes y la inmigración, se juntan en otras obras del autor, que analiza los ecos de este vínculo histórico en el presente migratorio en España, y específicamente en Cataluña, por medio del estudio del impacto de las representaciones del indígena marroquí en el periodo colonial en la concepción del migrante marroquí actual (2002), o las estrategias matrimoniales y el parentesco entre las clases populares marroquíes asentadas en Cataluña (2013).

En esta misma perspectiva historiográfica puede señalarse el trabajo de López García y Ramírez (2002) sobre la obra de una de estas figuras coloniales, el médico Felipe Ovilo, autor de cierta protoetnografía a últimos del siglo XIX, o la más reciente edición crítica de Martínez Antonio (2009) sobre los usos y costumbres en Marruecos desde la mirada de tres médicos del siglo XIX, así como una antología sobre la antropología en Marruecos (Ramírez y López 2002), que pretendía reunir los trabajos etnográficos de autoría marroquí, francesa, norteamericana y española a modo de homenaje a uno de los grandes antropólogos olvidados de Marruecos, David M. Hart. Como a Caro Baroja, su condición periférica —académicamente hablando- le situó en una posición marginal que dificultó que su obra fuera más conocida y que hiciera de puente entre la vieja antropología colonial y la moderna antropología española sobre Marruecos. Si Hart ha sido editado y si ha habido un empeño por recuperar ese legado, ha sido gracias al antropólogo José Antonio González Alcantud, quien

\footnotetext{
${ }^{15}$ Mateo Dieste tiene un texto sobre las relaciones entre antropología e historia (Mateo y Coello de la Rosa 2016).
} 
también con una fuerte impronta de los estudios históricos, dirigió desde el Centro de Investigaciones Etnológicas Ángel Ganivet de Granada una línea editorial que pretendía recuperar, editar críticamente y difundir estos materiales. El trabajo de González Alcantud es además ineludible en los estudios de orientalismo y exotismo (2002, 2004 y 2006), siempre en relación con Marruecos, así como en el trabajo sobre etnohistoria colonial (2003 y 2008).

Es importante destacar aquí la intersección entre antropología del islam y antropología médica, en una tradición que recoge y recupera aspectos clásicos de las temáticas de la etnología colonial, como los trabajos que desarrolla Mateo (2008 y 2013) en el abordaje de la salud, santería y prácticas de curación marroquíes, o los de González Vázquez (2015), también en el norte de Marruecos, pero con etnografía en un entorno rural sobre los yenún ${ }^{16}$ y su existencia entre las mujeres.

Continuando con las etnografías en las zonas rurales de Marruecos, hay que señalar dos más recientes, situadas en el marco de los efectos del neoliberalismo en Marruecos. Una de ellas, desde la economía feminista, analiza la alianza de la agricultura capitalista con las desigualdades de clase y género, a través del análisis del trabajo y de las relaciones sociales de las trabajadoras agrícolas en el norte de Marruecos (Moreno Nieto 2014 y 2017). La segunda se ocupa de otra alianza del neoliberalismo, la que establece con los modos tradicionales de gestión y herencia del usufructo de las tierras colectivas y sus consecuencias para las mujeres (Ramírez 2017). En los dos trabajos son fundamentales las estrategias de respuesta de las mujeres, tanto en el nivel de movilización política como en las formas de representación del mundo.

Aunque las instituciones nunca estimularon los estudios en general de la temática de esta cartografía, hay que señalar el impacto de las políticas mediterráneas de la Generalitat catalana en la producción académica sobre el norte de África y sobre la inmigración marroquí en España. Los objetivos de la política de Vecinazgo de la Unión Europea sirven de base para los intereses empresariales de la Generalitat en el Mediterráneo y se funda en 1989 el Institut Català d'Estudis Mediterranis, un think tank autónomo de la Generalitat catalana ${ }^{17}$, cuya sección de seminarios y publicaciones dirigió la antropóloga Maria Angels Roque. El interés y la disposición de presupuesto para organizar encuentros y publicar textos, supuso un estímulo importante en la construcción de redes desde Cataluña y en la difusión de trabajos sobre el Magreb y las migraciones a lo largo de la década de los años 90 y hasta bien entrados los 2000 . Especialmente importante fue el refuerzo de relaciones con antropólogos marroquíes, así como los congresos celebrados a ambos lados del Estrecho. Roque y su equipo, con una formación antropológica que debía mucho a la antropología francesa del Magreb, abrieron varias líneas de libros y revistas, que hoy en día siguen funcionando, como Afkar o Quaderns de la Mediterrània. Pensamos que ha tenido especial relevancia su trabajo pionero sobre mujeres en Marruecos (2000, 2006a, 2006b, 2013

\footnotetext{
${ }^{16}$ Los yenún, en singular yin (escrito tal y como se pronuncia, sin empleo de sistemas de transcripción) son una especie de espíritus malignos de la tradición popular en muchos países árabes, que conviven de manera cotidiana con las personas y a los que hay que saber tratar para que no se conviertan en fuente de males de todo tipo.

${ }^{17}$ Desde 2002 el Institut pasa a ser un órgano consorciado con Ayuntamiento de Barcelona y el Ministerio de Asuntos Exteriores y pasa a llamarse Institut Europeu de la Mediterrània.
} 
y 2016) como admiradora de la socióloga Fatima Mernissi, y su rescate de la cuestión amazigh (2002 y 2009), de gran relevancia en Cataluña, no solo por el gran volumen de inmigración rifeña que allí reside, sino por la conexión de lo amazigh con la cuestión nacional catalana desde una parte de los ambientes académicos. Igualmente es relevante señalar su interés por sostener la tensión con la tradición de la antropología mediterraneísta y debatir con las etnografías clásicas, desde Caro Baroja a PittsRivers o Boissevain. También en esta línea mediterránea hay que mencionar a la antropóloga Danielle Provansal que, como gran conocedora de la tradición etnológica franco-magrebí, hizo algunas aportaciones en esta línea (1997), añadiendo análisis específicos de Argelia sobre colonialismo y nuevas naciones (2004), estados de la cuestión sobre etnología franco-magrebí (2002a) o inmigración magrebí en Almería (Provansal 1997 y 2002b), sosteniendo una inédita Antropología del Magreb como asignatura en la Universitat de Barcelona desde principios de los años 90 hasta su jubilación, en 2005, cuando comenzó a ser asumida por López Bargados.

Aunque como se ha dicho, el análisis de los procesos migratorios se va diluyendo en otras temáticas diversas, hay que mencionar los trabajos sobre la frontera entre Marruecos y España a partir de dos autoras. La primera, Natalia Ribas, socióloga de la inmigración y la globalización con una extensísima obra, incluyendo una monografía sobre migraciones femeninas procedentes de diferentes países, entre los que se cuenta Marruecos. Ribas (1999) ha trabajado la cuestión de la frontera como un espacio histórico y un micro-paisaje desde el que observar las movilidades globales, trabajando con el carácter específico de las ciudades fronterizas (2001 y 2005). La segunda, la antropóloga Mercedes Jiménez, ha trabajado sobre las relaciones entre esta frontera y la infancia vulnerable, especialmente menores no acompañados, desde una larga etnografía en la ciudad de Tánger y su enorme conurbano (entre todos sus trabajos destacamos 2003 y 2011; además del realizado junto a Ángeles Ramírez en 2005). Jiménez además ha realizado y realiza una imprescindible labor académica de comunicación y enlace entre las universidades de ambos lados del Estrecho, trabajo necesario que sigue suponiendo una gran dificultad.

En un desplazamiento más al sur, es necesario mencionar el interés de López Bargados por el sistema de facciones y las tribus en el norte de África (2002) y la sociedad mauritana contemporánea (2005a, 2006b y 2009), así como por el Sahara colonizado por España (2003 y 2005b), en un enfoque de intersección entre la antropología del islam y la antropología política. Es interesante señalar que los estudios sobre el Sahara occidental y los campamentos de personas refugiadas en Tindouf (Argelia) han solido mantenerse fuera del ámbito de los estudios de esta cartografía, como si pertenecieran a otro ámbito disciplinar, quizás en virtud de la cercanía a Marruecos y de la imposibilidad de hacer etnografía en los dos lugares a la vez por el control que ejerce el Estado marroquí sobre el Sahara. Es ineludible sin embargo la consideración de los trabajos de los antropólogos y antropólogas del Sahara (Solana 2017; Gimeno Martín 2016; Gimeno y Robles 2013), que desde la economía política ofrecen visiones críticas de la historia postcolonial y de la construcción del Sahara postrevolucionario en los campamentos de personas refugiadas en Tindouf, constituyendo un magnífico ejemplo de antropología comprometida. Y en unas coordenadas geográficas mucho más alejadas, también en el mundo árabe, hay que mencionar la etnografía que Ewa Strzelecka (2017) realizó durante algunos años, que analiza el 
asociacionismo y las luchas de las mujeres yemeníes en un contexto de guerra civil, antes de integrarse como parte de un equipo de investigación sobre el Gran Sahara, liderado por el antropólogo Francisco Freire, de la Universidade Nova de Lisboa.

\section{EL FUTURO: SOSPECHA, VIOLENCIA Y LA ISLAMOFOBIA COMO MARCO}

Esta última vertiente teórica es aquella con la que pretenden dialogar nuevas generaciones de antropólogas y antropólogos que han comenzado sus estudios en este campo de antropología del islam y de contextos musulmanes en la última década. Un ejemplo de ellas es Virtudes Téllez Delgado quien ha estudiado las respuestas de la juventud musulmana madrileña ante los atentados del 11 de marzo de 2004 en Madrid por medio de la creación de asociaciones socioculturales desde las que cuestionar la asociación entre violencia e islam y plantear la posibilidad de conciliar identificaciones civil española y religiosa musulmana (2008, 2009, 2010, 2011a, 2011b, 2014a, 2014b y 2017). Junto a su trabajo, destaca en espejo el de Mariana Tello Weiss que aunque no ha continuado en esta línea de investigación, realizó una gran contribución a la misma con su análisis de las formas de representación mediática del perfil de los actualmente llamados terroristas yihadistas (2007). En este enfoque de la sospecha, es importante mencionar los análisis realizados sobre colectivos musulmanes que por su interpretación y práctica de la religiosidad islámica son mirados desde un mayor recelo y con más suspicacias: los salafíes y la Yamaa'at at-Tabligh. Ramírez (2016) y Moreras (2017b) tienen también una reflexión sobre este respecto. Hay que destacar la etnografía de largo recorrido de la antropóloga Sol Tarrés, quien inicia el análisis del último colectivo mencionado (2003) y retoma su interés por él posteriormente (2012); también sobre este grupo ha trabajado, con una producción aún incipiente, un representante de la nueva generación, Guillermo Martín Sáiz (2014).

La sospecha se asocia en el presente a la visibilización de la religiosidad islámica en el espacio público, por lo que son importantes los análisis realizados sobre los rituales islámicos. Pueden mencionarse los trabajos sobre los ritos funerarios de Sol Tarrés (2006), la aparición de los cementerios musulmanes en España como lugares de alteridad (Moreras y Tarrés 2012) y patrimonio cultural funerario (Tarrés y Moreras 2017), los rituales funerarios transnacionales (Solé 2012, 2014, 2015 y 2017), el ritual del Eid al adha (Alonso 2008), el Ramadán (Alonso y Solé 2012) y las manifestaciones particulares de los rituales islámicos en Cataluña (Alonso et al. 2015). Hay que nombrar también el trabajo de Salvatore Madonia (2017), quien analiza las implicaciones identitarias y los significados de la participación sociopolítica de los y las jóvenes musulmanes en Madrid, en reivindicaciones presentes, del calado del 15-M, y de Óscar Salguero Montaño (2018), que usa un interesante enfoque en su último trabajo en el que trata de indagar desde los estudios urbanos en la relación entre la visibilización del islam y los espacios públicos desde una perspectiva diacrónica en el caso de la fronteriza ciudad de Melilla.

De este modo, podemos indicar tres ejes temáticos que han guiado la literatura académica en este campo de la disciplina. En primer lugar, ha habido una asociación directa entre musulmán y migrante, destacando entre ellos el origen marroquí, como es el caso de los estudios mencionados más arriba. En segundo lugar, como un modo lógico de gestión de las migraciones y de las personas migrantes, se observa un inte- 
rés por la integración de las mismas, manifestado aquí por las reflexiones sobre la gestión del islam (a modo de ejemplo, Moreras 2001a, 2001b, 2002a, 2002b, 2003a, 2004, 2005b y 2006a; Tarrés 2002 y 2005; Mijares y Ramírez 2005, 2008a y 2008b; Dietz, Rosón y Ruiz 2011; Tarrés y Rosón 2014a, 2014b y 2017; Tarrés y Moreras 2017), inserta en un marco más amplio de gestión del pluralismo religioso en la sociedad contemporánea $^{18}$ (Rosón 2002, 2008a y 2008b; Moreras 2006b; Estruch et al. 2007; Buades y Vidal 2007; López García et al. 2007; Díez de Velasco 2008; Gómez Bahillo 2009; Hernando de Larramendi y García 2009; Tarrés y Rosón 2009; Briones 2010; Ruiz Vieytiz 2010; Montes y Martínez 2011; Astor 2012; Lasheras 2012; Tarrés y Jiménez de Madariaga 2012; Valero 2012; Briones, Tarrés y Salguero 2013; Izquierdo 2014; Astor y El-Bachouti 2015; Astor y Griera 2016; Buades 2016; Urrutia 2017). Finalmente, en tercer lugar, se abre un campo de reflexión sobre la representación de las personas musulmanas, ancladas aún a un pasado migratorio, o ciudadanas de hecho y derecho, pero que con independencia de su condición político-administrativa, son puestas bajo sospecha con el argumento de la amenaza de radicalización y su posible vinculación al llamado terrorismo yihadista. En este último sentido se abre un debate sobre el rechazo que se deriva de estas formas de representación, bajo la categoría de islamofobia o racismo antimusulmán, como formas de violencia simbólica, política y estructural. El contexto catalán y europeo es trabajado específicamente en López Bargados (2009), que analiza las lógicas de control, construcción de la sospecha y vigilancia con las que se negocia, representa y ejerce el poder sobre todas las personas - percibidas como- musulmanas en la actualidad, y que dan como resultado la génesis de un sujeto subalterno presentado a la ciudadanía como una amenaza vehiculada por medio del yihadismo (2016 y 2018).

No hay mucha producción aún sobre la relativamente nueva temática de la islamofobia en España. La obra más extensa, fuera de la antropología, es la del historiador Fernando Bravo (2012), que trabaja sobre la construcción discursiva de la islamofobia en relación con el antisemitismo, elaborando una completa genealogía de este proceso en España. En las ciencias sociales, las nuevas líneas de reflexión ponen en relación los modelos seculares con prácticas islamófobas (López Bargados 2018). Una línea de análisis de este debate es la discusión sobre el origen de la islamofobia, con implicaciones políticas y disciplinares. Se puede decir que hay una línea que tomando prestados los ineludibles trabajos del historiador Martín Corrales (2002 y 2004) sobre la imagen del moro desde el siglo XVII y sobre la maurofobia en España, reduce la islamofobia a esto último (Zapata Barrero 2006), lo que supone finalmente una negación de este nuevo racismo, que termina de algún modo culturalizándolo y entroncándolo con una difusa tradición ibérica. Las similitudes entre la maurofobia de la España moderna y la islamofobia contemporánea no deberían llevar, por comodidad intelectual, a asumir el carácter inmanente de esta construcción del islam y de musulmanas y musulmanes (López Bargados 2016). Si se asume que siempre ha existido este odio como una característica de la historia social de España, de occi-

\footnotetext{
${ }^{18}$ La Fundación Pluralismo y Convivencia, del Ministerio de Justicia, encargó durante las dos primeras décadas del 2000, una serie de investigaciones sobre las religiones no católicas representadas en las diferentes comunidades autónomas. El resultado es un grupo de estudios que dan cuenta de esta diversidad religiosa, en la que el islam tiene un papel importante. Sus referencias están incluidas entre otras obras citadas aquí.
} 
dente, o del territorio que fuere, se está aceptando implícitamente que se trata de un conjunto de planteamientos culturales, identitarios, que son independientes de las circunstancias históricas, políticas y sociales. En este sentido, es útil reconstruir las diferentes posiciones de Edward Said (2003 [1978]) y de Maxime Rodinson (1980) sobre el orientalismo. El primero analizó las obras literarias de los grandes autores clásicos occidentales - los escritos de los orientalistas - mostrando cómo se articulaba un discurso que estigmatizaba a los orientales y que construía un oriente preparado para ser colonizado, destruido y domesticado, como parte fundamental de la identidad de un occidente opuesto. Sin embargo, la interpretación más extendida de Said —a la que él no se opuso- apunta a una suerte de culturalismo que sostiene de modo ahistórico una matriz orientalista (López Bargados 2016) homogénea y esencial. La perspectiva de Rodinson, que no es un crítico literario como Said, sino historiador, sitúa las relaciones entre oriente y occidente en un ámbito histórico y político, y eso le permite analizar las discontinuidades y rupturas en esa relación con lo árabe y lo musulmán en diferentes momentos históricos.

Otros análisis actuales — hegemónicos en la academia a día de hoy- vienen a apuntalar aquella primera línea de interpretación culturalista sobre la islamofobia ${ }^{19}$ (Martín Muñoz 2012; Grosfoguel 2014). En ruptura epistemológica con esta interpretación y mucho más cercano al análisis de Rodinson, se sitúa el texto de Mateo Dieste (2017), que recompone la historia de estos estereotipos y de esa reactualización del racismo. Este es también uno de los hilos de la red internacional de los Orientalismos periféricos, liderada por la antropóloga portuguesa Maria Cardeira y que reúne a investigadoras e investigadores (básicamente en la antropología, pero no únicamente) de países periféricos en la producción orientalista (Portugal, España, Brasil, Argentina, Italia o México), con el objeto de reflexionar sobre estas representaciones y procesos. Una muestra de esta producción, la mayoría inédita, puede verse en el número 21 de la Revista de Estudios Internacionales Mediterráneos (REIM), mencionada más arriba. En tercer término, hay una serie de trabajos que también confrontando la primera línea, pretenden fundamentar etnográficamente no solo la islamofobia y su conformación por parte de las instituciones, sino las respuestas y los repertorios de la resistencia de las poblaciones musulmanas (Ramírez 2014). La reflexión sobre la islamofobia ha sido reubicada en trabajos recientes en intersección con las relaciones de clase (López Bargados y Ramírez 2015) y las estructuras patriarcales (Ramírez y Mijares 2018). Las respuestas y formas de resistencia se ha analizado recientemente a través del cuestionamiento del papel de la musulmaneidad en la movilización política de personas musulmanas (Mijares y Lems 2018). La cuestión del pañuelo más allá del islam, en el centro de los racismos de Estado y de los regímenes abiertamente patriarcales como una forma de control de la población musulmana y de las mujeres, ha sido tratada en Ramírez (2011 y 2015). Ahondando en esta cuestión, es interesante la mención del concepto de islamofobia de género, que fue construido por Zine

\footnotetext{
19 En este sentido, hay un debate más profundo sobre el uso del término islamofobia o su otra opción, racismo antimusulmán. Si bien islamofobia visibiliza un tipo particular de racismo contra las personas musulmanas, puede hacer aparecer con demasiado énfasis la cuestión religiosa, eliminando las componentes más clásicas de cualquier racismo (clase y género) y desconectándolo como proceso de las condiciones políticas, sociales, económicas o culturales en las que tiene lugar específicamente (López Bargados y Ramírez 2015).
} 
(2006) y trabajado para el caso español por Mijares y Ramírez (2008b), el cual define las formas específicas de discriminación étnico-religiosa y racializada dirigidas hacia las mujeres musulmanas, que proceden de estereotipos negativos construidos históricamente y que forman parte tanto de las opresiones individuales como de las sistémicas. Finalmente, Aixelà (2012) enmarca el análisis del cuerpo musulmán de hombres y mujeres, especialmente del pañuelo musulmán, en el centro de la cuestión identitaria y vinculado a las cuestiones de integración e islamofobia, en un interesante análisis en contextos migratorios, pero sin perder de vista Marruecos.

Avanzando más allá de los cuerpos individuales y de los procesos migratorios, se ha publicado recientemente un monográfico específico sobre islamofobia y racismo antimusulmán (REIM), donde la entronización de estas prácticas protagoniza los distintos artículos que lo componen, dedicados al análisis de la institucionalización jurídica y política de la sospecha hacia las personas musulmanas por medio de dispositivos específicos. En primer lugar, del llamado Pacto Antiyihadista (Téllez 2018); en el segundo, de los razonamientos jurídicos de las dos altas instancias jurídicas europeas (Relaño 2018); en el tercero, de los argumentos de la izquierda política sobre el islam y los musulmanes (Gil-Benumeya 2018); en el cuarto, de la instrumentalización de los sujetos queer por las políticas neoliberales para promover la representación LGBTIQ+fóbica del islam (Ahmed 2018); en quinto lugar, del Plan Municipal contra la Islamofobia, implementado por la administración municipal de Barcelona y su compatibilidad o incompatibilidad con los "imaginarios seculares" de Göle (2015; López Bargados 2018); y finalmente, en un artículo basado sobre la realización de grupos de discusión, dos de las coordinadoras del monográfico indagan en la relación entre la conciencia de subalternidad por parte de la población musulmana y su musulmaneidad, explorando la posible articulación de esta condición con los tipos de lucha contra la islamofobia o racismo antimusulmán (Mijares y Lems 2018).

\section{ALGUNAS (NO) CONCLUSIONES}

Llegamos al final de un texto que sobrepasó nuestras propias expectativas en cuanto al espacio y también a las dudas sobre su enfoque. Hemos aprendido algunas cosas más, como los enormes débitos de nuestra antropología con otras disciplinas, principalmente con los estudios orientalistas, llevados desde el arabismo y la historia especialmente, de los que las ciencias más modernas en España, como la sociología, las ciencias políticas y la antropología, han ido bebiendo en todos estos años.

Por entender que aún está en plena consolidación, hemos dejado fuera de la cartografía algunas temáticas muy nuevas, como toda la investigación generada sobre el estallido de las primaveras árabes y su impacto en los contextos migratorios, que ha forzado a fijar la vista no solo en lo acontecido desde 2011, sino en los focos de protesta y activismos siempre vivos en los diferentes rincones del área.

Como buen dilema, el que nosotras planteamos en este texto es irresoluble. Trabajamos desde la etnografía para parecernos al antropólogo de Gellner y romper con la reproducción de estereotipos y esencializaciones, al tiempo que como su orientalista, somos capaces de hablar de los musulmanes o del islam o de referirnos a cualquier aspecto o lugar donde haya población musulmana. Pero tampoco deberíamos pare- 
cernos a Gellner, con sus esencialismos sobre árabes y bereberes. Quizá es algo de lo que ninguna antropología puede escapar. Para nosotras, esta relación conflictiva es también una oportunidad de reflexión sobre los temas clave de la disciplina, como la construcción de la alteridad, la reificación y nuestro papel y responsabilidad en la reproducción de los estigmas que pesan sobre algunas poblaciones. En este último sentido, el final del recorrido de este texto muestra el compromiso creciente de antropólogas y antropólogos con la denuncia de la estigmatización y de las distintas formas en que se ejerce el racismo antimusulmán o islamofobia en el seno del Estado español. Por eso, nos parecen contraproducentes los enfoques —ahora hegemónicos en muchas academias- que culturalizan el racismo y lo terminan banalizando, desgajándolo de las condiciones materiales y simbólicas en las que se produce. Y por supuesto, también denunciamos la daeshización de la investigación sobre islam y el hecho de que cada vez más se primen encuentros y publicaciones sobre esa conceptualización del léxico securitario, como son los supuestos procesos de radicalización. Confiemos en seguir haciendo y disponiendo de una antropología que sea capaz de desbordar lo académico a partir de la teoría; y de la etnografía.

\section{BIBLIOGRAFÍA CITADA}

Abu-Lughod, Lila. 2013. Do Muslim Women Need Saving? Cambridge/Londres: Harvard University Press. Aixelà Cabré, Yolanda. 2000. Mujeres en Marruecos: un análisis desde el parentesco y el género. Barcelona: Bellaterra.

Aixelà Cabré, Yolanda. 2012. "La presentación social del cuerpo marroquí en contextos migratorios. Entre la afirmación identitaria y el rechazo islamófobo". Revista de Dialectología y Tradiciones Populares 57(1): 19-48. doi: <https://doi.org/10.3989/rdtp.2002.v57.i1>.

Allievi, Stephano. 2006. "How and Why "Immigrants" Became "Muslims". ISIM Review 18: 37. Disponible en: <https://openaccess.leidenuniv.nl/handle/1887/10077>. Fecha de acceso: 19 may. 2018.

Alonso Cabré, Marta. 2008. "Missatges autorreferencials dels actors del ritual de l'Id-al-ad-ha". (Con)textos: Revista d'Anropologia i Investigació Social 2: 73-92. Disponible en: <https://dialnet.unirioja.es/servlet/ articulo?codigo=2873974>. Fecha de acceso: 19 may. 2018.

Alonso Cabré, Marta y Ariadna Solé. 2012. "El Ramadán en Cataluña: Salud y ayuno en diáspora”, en Mabel Gracia Arnaiz (coord.), Alimentación, salud y cultura: Encuentros interdisciplinares: 341-357. Tarragona: Universitat Rovira i Virgili.

Alonso Cabré, Marta, Khalid Ghali, Alberto López Bargados, Jordi Moreras y Ariadna Solé. 2015. "Islamic Rituals in Diáspora: Muslim Communities in Catalonia". Revista d'Etnologia de Catalunya 40: 40-46. Disponible en: <http://cultura.gencat.cat/ca/detall/Noticies/N_REC40>. Fecha de acceso: 19 may. 2018.

Asad, Talal. 1986. The Idea of an Antbropology of Islam. Washington: Center for Contermporany Arab Studies, Georgetown University.

Astor, Avi. 2012. "Context i conflicto: anàlisi de les fonts d'oposició entorn de les mesquites a Catalunya". Revista Catalana de Sociologia 28: 45-59. Disponible en: <http://blogs.iec.cat/acs/2012/12/31/revistacatalana-de-sociologia-num-28-2/>. Fecha de acceso: 19 may. 2018.

Astor, Avi y Mohammed El-Bachouti. 2015. "Estructuras de oportunidad y políticas de interculturalidad: la gobernanza del islam en la España contemporánea", en Ricard Zapata Barrero e Irena Guidokova (coord.), Las condiciones de la interculturalidad: gestión local de la diversidad de España: 221-242. Valencia: Tirant lo Blanch.

Astor, Avi y Mar Griera. 2016. "La gestión de la diversidad religiosa en la España contemporánea”. Anuario CIDOB de la Inmigración 2016: 248-270. doi: <https://doi.org/10.24241/AnuarioCIDOBInmi.2016>.

Azurmendi, Mikel. 2001. Estampas de El Ejido. Un reportaje sobre la integración del inmigrante. Barcelona: Taurus.

Baroudi, Abdallah. 1978. Maroc: Imperialisme et Emigration. París: Le Sycomore. 
Bowen, John R. 2012. A New Anthropology of Islam. Cambridge: Cambridge University Press.

Bravo López, Fernando. 2012. En casa ajena. Bases intelectuales del antisemitismo y la islamofobia. Barcelona: Bellaterra.

Briones, Rafael (dir.). 2010. ¿Y tú (de) quién eres? Minorías religiosas en Andalucía. Barcelona: Icaria.

Briones, Rafael, Sol Tarrés y Óscar Salguero. 2013. Encuentros: Diversidad religiosa en Ceuta y Melilla. Barcelona: Icaria.

Buades, Josep. 2016. Amic(s) e amat(s). Minorías religiosas en las Illes Balears. Barcelona: Icaria.

Buades, Josep y Fernando Vidal. 2007. Minorías de lo mayor. Minorias religiosas en la Comunidad Valenciana. Barcelona: Icaria.

Cardeira da Silva, Maria. 1999. Um Islao Prático. Oeiras: Celta.

Cardeira da Silva, Maria. 2008. "As mulheres, os outros e as mulheres dos outros: feminismo, academia e Islao". Cadernos do Pagu 30(1): 137-150. doi: <https://doi.org/10.1590/S0104-83332008000100011>.

Cardeira da Silva, Maria. 2016. "Southern insights into Orient and Western Orientalism". Revista de Estudios Internacionales Mediterráneos (REIM) 21: 1-11. doi: <https://doi.org/10.15366/reim2016.21>.

Caro Baroja, Julio. 1957. Estudios mogrebies. Madrid: CSIC.

Caro Baroja, Julio. 1990. Estudios Saharianos. Madrid: Editorial Júcar.

Castien Maestro, Juan Ignacio. 2003. Las astucias del pensamiento. Creatividad ideológica y adaptación social entre los inmigrantes marroquies en la Comunidad de Madrid. Madrid: Consejo Económico y Social.

Castien Maestro, Juan Ignacio. 2014. «Etnias, tribus y cofradías. La sociedad mauritana en su interacción con el Estado", en Mauritania: nuestro vecino del sur, un estudio geopolitico en red: 19-56. Documentos de Seguridad y Defensa n.․ 65. Madrid: Escuela de Altos Estudios de la Defensa, EALEDE/Centro de Estudios Superiores de la Defensa Nacional, CESEDEN.

Castien Maestro, Juan Ignacio. 2015a. «Modernización y regresión en Afganistán. Un ensayo de interpretación". Revista del Instituto Español de Estudios Estratégicos 5. Disponible en: <http://revista.ieee.es/ index.php/ieee/article/view/171/342>. Fecha de acceso: 16 may. 2018.

Castien Maestro, Juan Ignacio. 2015b. "Tribalismo, islam y cambio social en el Sáhara Occidental”, en Luis Ángel Aparicio-Ordás González-García, Juan Ignacio Castien Maestro, Mamadou Cheikh Agne, Juan Mora Tebas, Emilio Sánchez de Rojas Díaz et al., Nuestra frontera más avanzada entre el Sáhara Occidental y Senegal: 117-153. Monografía n. ${ }^{\circ}$ 145. Madrid: Escuela de Altos Estudios de la Defensa, EALEDE/Centro de Estudios de la Defensa Nacional, CESEDEN.

Castien Maestro, Juan Ignacio. 2016. "Islam e identidad nacional en el Senegal Contemporáneo". Papeles del CEIC. International Journal of Colective Identity Research 2: 1-27. doi: <https://doi.org/10.1387/ pceic.16144>.

Dietz, Gunther, Javier Rosón y Francisca Ruiz Garzón. 2011. «Homogeneidad confesional en tiempos de pluralismo religioso: Una encuesta cualitativa con jóvenes españoles sobre religión y educación". Revista CPU-e 13: 2. Disponible en: <https://www.uv.mx/cpue/num13/inves/Dietz_homogeneidad\%20 confesional.html>. Fecha de acceso: 17 may. 2018.

Díez de Velasco, Francisco (dir.). 2008. Religiones entre continentes. Minorias religiosas en Canarias. Barcelona: Icaria.

Eickelman, Dale F. 1989 [1981]. The Middle East. An Anthropological Approach. Englewood Cliffs: Prentice Hall.

Estruch, Joan, Joan Gómez i Segalà, María del Mar Griera y Agustí Iglesias. 2007. Las otras religiones: Minorias religiosas en Cataluña. Barcelona: Icaria.

Fernández, Daniel Ahmed. 2018. "Islamofobia queerizada y resistencias musulmanas queer en tiempos de homonacionalismo", en Laura Mijares, Johanna M. Lems y Virtudes Téllez (coords.), Islamofobia y racismo antimusulmán: un análisis multidisciplinar desde las prácticas: 71-88. Número monográfico de la Revista de Estudios Internacionales Mediterráneos (REIM) 24. doi: <https://dx.doi.org/10.15366/ reim2018.24.005>.

Franzé, Adela. 1996. "La población infantil marroquí en la escuela española", en Bernabé López, Ana I. Planet y Ángeles Ramírez (coords.), Atlas de la inmigración magrebi en España: 218-220. Madrid: Universidad Autónoma de Madrid/Observatorio Permanente de Migraciones. Disponible en: <http:// extranjeros.empleo.gob.es/es/ObservatorioPermanenteInmigracion/Publicaciones/OtrosDocumentos/ atlas/index.html>. Fecha de acceso: 15 may. 2018. 
Franzé, Adela. 2002. "Lo que sabía no valia”: escuela, diversidad e inmigración. Madrid: Consejo Económico y Social.

Franzé, Adela y Laura Mijares (eds.). 1999. Lengua y cultura de origen: niños marroquíes en la escuela española. Madrid: Ediciones del Oriente y del Mediterráneo.

Geertz, Hildred. 1978. "The Meaning of Family Ties", en Clifford Geertz (ed.), Meaning and Order in Moroccan Society: Three Essays in Cultural Analysis: 325-379. Cambridge: Cambridge University Press.

Geisser, Vincent. 2012. "La "question musulmane" en France au prisme des sciences sociales". Cahiers d'Études Africaines 206-207: 351-366. Disponible en: <http://journals.openedition.org/etudesafricaines/ 17041>. Fecha de acceso: 9 may. 2018.

Geisser, Vincent. 2016. "Gilles Kepel hanté par l'islamisation de la France". Orient XXI 15 ene. Disponible en: <http://orientxxi.info/lu-vu-entendu/gilles-kepel-hante-par-l-islamisme,1149>. Fecha de acceso: 16 may. 2018.

Gellner, Ernest. 1986 [1981]. La sociedad musulmana. México: Fondo de Cultura Económica.

Gil-Benumeya, Daniel. 2018. "Viejas políticas y nuevos racismos. La izquierda frente a la islamofobia", en Laura Mijares, Johanna M. Lems y Virtudes Téllez (coords.), Islamofobia y racismo antimusulmán: un análisis multidisciplinar desde las prácticas: 49-70. Número monográfico de Revista de Estudios Internacionales Mediterráneos (REIM) 24. doi: <https://dx.doi.org/10.15366/reim2018.24.004>.

Giménez Romero, Carlos. 1991. "Trabajadores extranjeros en la agricultura española: enclaves e implicaciones". Revista de Estudios Regionales 31: 127-148. Disponible en: <http://www.revistaestudios regionales.com/documentos/articulos/pdf358.pdf>. Fecha de acceso: 19 may. 2018.

Giménez Romero, Carlos. 1994. "Magrebíes, agricultura y marginación en el litoral valenciano", en Andrés Sánchez Picón (coord.), Agriculturas mediterráneas y mundo campesino: cambios históricos y retos actuales. Actas de las Jornadas de Historia Agraria: 177-190. Almería: Instituto de Estudios Almerienses. Disponible en: <https://dialnet.unirioja.es/servlet/articulo?codigo=2242647>. Fecha de acceso: 19 may. 2018.

Gimeno Martín, Juan Carlos. 2016. “Elegir entre paz y justicia? Apuntes para la resolución del conflicto del Sahara occidental". Revista Andaluza de Antropología 10: 167-191. Disponible en: <http:// www.revistaandaluzadeantropologia.org/uploads/raa/n10/gimeno.pdf>. Fecha de acceso: 16 may. 2018.

Gimeno Martín, Juan Carlos y Juan Ignacio Robles Picón. 2013. "Ambivalencia y orden colonial español en el Sahara Occidental: (1969-1973)". Revista Andaluza de Antropología 5: 151-177. Disponible en: <http://www.revistaandaluzadeantropologia.org/uploads/raa/n5/raa5/gimeno.pdf>. Fecha de acceso: 16 may. 2018.

Göle, Nilufer. 2015. Islam and Security. Londres: Duke University Press. doi: <https://doi.org/10.1215/ 9780822375135>.

Gómez Bahillo, Carlos (coord.). 2009. Construyendo red. Minorías religiosas en Aragón. Barcelona: Icaria.

González Alcantud, José Antonio. 2002. Lo moro. Las lógicas de la derrota y la formación del estereotipo islámico. Barcelona: Anthropos.

González Alcantud, José Antonio (coord.). 2003. Marroquies en la guerra civil española. Campos equívocos. Granada: Anthropos.

González Alcantud, José Antonio. 2004. Deseo y negación de Andalucía. El peso de lo local y la contraposición Oriente/Occidente en la realidad andaluza. Granada: Universidad de Granada.

González Alcantud, José Antonio (coord.). 2006. El orientalismo desde el Sur. Sevilla: Anthropos.

González Alcantud, José Antonio (coord.). 2008. La ciudad magrebi en tiempos coloniales. Barcelona: Anthropos.

González Vázquez, Araceli. 2015. Mujeres, Islam y Alteridades en el Norte de Marruecos. Barcelona: Bellaterra.

Gregorio Gil, Carmen. 1996. "La intervención social con inmigrantes magrebíes: en busca de la anhelada "integración”", en Bernabé López García, Ana I. Planet y Ángeles Ramírez (coords.), Atlas de la inmigración magrebi en España: 226-228. Madrid: Universidad Autónoma de Madrid/Observatorio Permanente de Migraciones. Disponible en: <http://extranjeros.empleo.gob.es/es/ObservatorioPermanente Inmigracion/Publicaciones/OtrosDocumentos/atlas/index.html>. Fecha de acceso: 15 may. 2018.

Gregorio Gil, Carmen y Ángeles Ramírez Fernández. 2000. "¿En España es diferente...? Mujeres inmigrantes dominicanas y marroquíes". Papers. Revista de Sociología 60: 257-273. doi: <https://doi.org/10.5565/ rev/papers/v60n0.1042>. 
Grosfoguel, Ramón. 2014. "Las múltiples caras de la islamofobia”. Raíz Diversa 1(1): 83-114. Disponible en: <http://latinoamericanos.posgrado.unam.mx/publicaciones/deraizdiversa/no.1/grosfoguel.html>. Fecha de acceso: 20 may. 2018.

Hernández Corrochano, Elena. 2008. Mujeres y familia en el Marruecos modernizado. Madrid: Cátedra. Hernando de Larramendi Martínez, Miguel y Bárbara Azaola Piazza. 2006. "Los estudios sobre el Mundo Árabe y Mediterráneo Contemporáneos en España", en Iván Martín y Richard Gillespie (dirs.), Investigando el Mediterráneo: 87-148. Madrid: British Council/Fundación CIDOB/Instituto Europeo del Mediterráneo, IEMed.

Hernando de Larramendi, Miguel y Puerto García Ortiz (dirs.). 2009. Religion.es. Minorías religiosas en Castilla-La Mancha. Barcelona: Icaria.

Herzfeld, Michael. 1997. "Anthropology and the Politics of Significance". Social Analysis 41: 107-138.

Izquierdo, Antonio (dir.). 2014. Mareas de pluralismo. Minorias religiosas en Galicia. Barcelona: Icaria.

Jabardo, Mercedes. 1993. "Inmigrantes africanos en la agricultura del País Valenciá", en Bernabé López García (ed.), Inmigración magrebi en España. El retorno de los moriscos: 267-290. Madrid: Mapfre.

Jiménez Álvarez, Mercedes G. 2003. Buscarse la vida: análisis transnacional de los procesos migratorios de los menores marroquies no acompañados en Andalucía. Madrid: Ediciones SM.

Jiménez Álvarez, Mercedes G. 2011. Intrusos en la fortaleza: menores marroquies migrantes en la frontera sur de Europa. Tesis doctoral. Universidad Autónoma de Madrid.

Keddie, Nikki R. y Beth Baron. 1991. Women in Middle Eastern history: shifting boundaries in sex and gender. New Haven: Yale University Press. doi: <https://doi.org/10.1515/9781400845057-014>.

Kepel, Gilles. 2011. Banlieue de la République. París: Institut Montaigne.

Khosrokhavar, Farhad. 1997. L'islam des jeunes. París: Flammarion.

Lacomba, Joan. 1999a. "El islam y su práctica entre la inmigración magrebí: Transformaciones y adaptaciones". Ofrim suplementos 4: 147-164.

Lacomba, Joan. 1999b. El juego entre la exclusión y la inserción en situación inmigrada: modificación y permanencia de la identidad cultural entre los inmigrantes musulmanes. Tesis doctoral. Universitat de València.

Lacomba, Joan. 2000. "La inmigración musulmana y el islam institucionalizado: la figura de los imames inmigrados". Migraciones 7: 155-194. Disponible en: <http://revistas.upcomillas.es/index.php/ revistamigraciones/article/view/4454>. Fecha de acceso: 19 may. 2018.

Lacomba, Joan. 2001a. "Inmigrantes senegaleses, islam y cofradías". Revista Internacional de Sociología 29: 163-187.

Lacomba, Joan. 2001b. El islam inmigrado: transformaciones y adaptaciones de las prácticas culturales y religiosas. Madrid: Subdirección General de Museos Estatales.

Lacomba, Jordi. 1996. «Identidad y religión en inmigración: a propósito de las estrategias de inserción de los musulmanes senegaleses". Alternativas: Cuadernos de Trabajo Social 4: 59-76. doi: <https://doi.org/ 10.14198/ALTERN1996.4.4>.

Lacomba, Jordi e Isabel Royo. 1997. «Una inmigración entre la precariedad y la exclusión: condiciones de vida de los inmigrantes marroquíes y senegaleses en situación irregular en el área urbana de Valencia". Servicios Sociales y Politica Social 37: 93-107.

Lacomba, Jordi. 1998. "Migraciones y Trabajo Social Intercultural: propuestas teóricas y metodológicas". Servicios Sociales y Política Social 44: 33-54.

Lasheras, Rubén. 2012. Umbrales. Minorías religiosas en Navarra. Barcelona: Icaria.

López Bargados, Alberto. 2002. "A la búsqueda de la tribu: los sistemas de facciones en el norte de África", en Ángeles Ramírez y Bernabé López García (coords.), Antropología y antropólogos en Marruecos: homenaje a David M. Hart: 449-460. Barcelona: Bellaterra.

López Bargados, Alberto. 2003. Arenas coloniales: los Awlad Dalim ante la colonización franco-española del Sáhara. Barcelona: Bellaterra.

López Bargados, Alberto. 2005a. «Primos públicos y ancestros privados: consideraciones sobre la noción de "tribu" en la sociedad mauritana contemporánea", en Albert Roca (coord.), La revolución pendiente: el cambio político en el África negra: 213-236. Lleida: Universitat de Lleida.

López Bargados, Alberto. 2005b. "Julio Caro Baroja en el Sáhara: los méritos de una "etnografía relámpago", en Jaime Alvar (coord.), Memoria de Julio Caro Baroja: 266-289. Madrid: Ministerio de Cultura. 
López Bargados, Alberto. 2006a. "Mauritania: cuatro paradojas y una coda". Quaderns de la Mediterrània. Cuadernos del Mediterráneo 6: 141-146.

López Bargados, Alberto. 2006b. "Marruecos, 1990-1991: variaciones sobre una tradición insurgente", en Laura Núñez (ed.), Momentos insurreccionales: revueltas, algaradas y procesos revolucionarios: 6586. Barcelona: El Viejo Topo.

López Bargados, Alberto. 2009. "Narrativas del miedo. Sobre la construcción de la amenaza islamista en Barcelona", en Abdennur Prado, Albert Martínez, Alberto López Bargados et al., Rastros de Dixan. Islamofobia y construcción del enemigo en la era post-11S. Barcelona: Virus.

López Bargados, Alberto. 2012. "Perfiles del "Far West” Sahariano: el papel de la frontera colonial en el Sahel atlántico (Sáhara Occidental, Mauritania)". Hesperis Tamuda 47: 19-38.

López Bargados, Alberto. 2016. "La amenaza yihadista en España: Viejos y nuevos orientalismos". Revista de Estudios Internacionales Mediterráneos (REIM) 21: 73-80. doi: <https://doi.org/10.15366/ reim2016.21.006>.

López Bargados, Alberto. 2018. «Barcelona, ¿ciudad islamófoba? Variaciones sobre las políticas seculares y el "problema musulmán", en Laura Mijares, Johanna M. Lems y Virtudes Téllez (coords.), Islamofobia y racismo antimusulmán: un análisis multidisciplinar desde las prácticas: 89-108. Número monográfico de Revista de Estudios Internacionales Mediterráneos (REIM) 24. doi: <https//doio.org/10.15366/ reim2018.24.006>.

López Bargados, Alberto y Josep Lluís Mateo Dieste. 2005. "Parler au desert: Bilan de L'anthropologie du Maghreb en Espagne”. Prologues. Revue Maghrébine du Libre 32: 110-125.

López Bargados, Alberto y Ángeles Ramírez. 2015. "Un decálogo a contracorriente sobre la islamofobia". Viento Sur: Por una izquierda alternativa 138: 19-26. Disponible en: <http://vientosur.info/ spip.php?article10046>. Fecha de acceso: 17 may. 2018.

López Bargados, Alberto y Raquel Ojeda. 2009. “E pur si muove?” Lógicas del poder y proceso de transición en la República Islámica de Mauritania", en Ferrán Izquierdo Brichs (coord.), Poder y regimens en el mundo árabe contemporáneo: 151-176. Barcelona: CIDOB.

López García, Bernabé. 2016. "Los arabistas españoles "extramuros” del orientalismo europeo (1820-1936)". Revista de Estudios Internacionales Mediterráneos (REIM) 21: 107-117. doi: <https://doi.org/10.15366/ reim2016.21.009>.

López García, Julián, Lorenzo Mariano Juárez y Francisco Xavier Medina. 2016. "Usos y significados contemporáneos de la comida desde la antropología de la alimentación en América Latina y España". Revista de Dialectología y Tradiciones Populares 71(2): 327-370. doi: <https://doi.org/10.3989/ rdtp.2016.v71.i2>.

López García, Bernabé, Ana I. Planet y Ángeles Ramírez (coord.). 1996. Atlas de la inmigración magrebí en España. Madrid: Universidad Autónoma de Madrid/Observatorio Permanente de Migraciones. Disponible en: <http://extranjeros.empleo.gob.es/es/ObservatorioPermanenteInmigracion/Publicaciones/ OtrosDocumentos/atlas/index.html>. Fecha de acceso: 15 may. 2018.

López García, Bernabé, Ana I. Planet y Ángeles Ramírez (coords.). 2004. Atlas de la inmigración marroquí en España. Madrid: Universidad Autónoma de Madrid/Observatorio Permanente de Migraciones. Disponible en: <http://extranjeros.empleo.gob.es/es/ObservatorioPermanenteInmigracion/Publicaciones/OtrosDocumentos/atlas/index.html>. Fecha de acceso: 15 may. 2018.

López García, Bernabé y Ángeles Ramírez. 2002. "Felipe Ovilo: testigo del cambio en el Marruecos de fines del siglo XIX", en Ángeles Ramírez y Bernabé López García (eds.), Antropología y antropólogos en Marruecos. Homenaje a David M. Hart: 157-170. Barcelona: Bellaterra.

López García, Bernabé, Ángeles Ramírez, Eva Herrero, Said Kirhlani y Mariana Tello. 2007. Arraigados. Minorias religiosas en la Comunidad de Madrid. Barcelona: Icaria.

Madonia, Salvatore. 2017. Jóvenes musulmanes españoles: Un estudio etnográfico en la Comunidad de Madrid. Tesis doctoral. Universidad Complutense de Madrid.

Mahmood, Saba. 2004. Politics of Piety: The Islamic Revival and the Feminist Subject. Princeton: Princeton University Press.

Martín Corrales, Eloy. 2002. La imagen del magrebi en España: una perspectiva histórica, siglos XVI-XX. Barcelona: Bellaterra.

Martín Corrales, Eloy. 2004. "Maurofobia/Islamofobia y maurofilia/islamofilia en la España del siglo XXI". Revista CIDOB d'Afers Internacionals 66-67: 39-51. Disponible en: <https://www.cidob.org/es/ 
publicaciones/serie_de_publicacion/revista_cidob_d_afers_internacionals/ representaciones_e_interculturalidad>. Fecha de acceso: 15 may. 2018.

Martín Díaz, Emma. 2002a. El Ejido, dos años después. Realidad, silencios y enseñanzas. Madrid: Talasa.

Martín Díaz, Emma. 2002b. "Cultivando la ilegalidad: mercado de trabajo e inmigración en las agriculturas andaluzas", en Pilar Almoguera (coord.), De sur a sur: análisis multidisciplinar del fenómeno migratorio en España: 117-144. Madrid: Agapea.

Martín Díaz, Emma y Margarita Rodríguez García. 1999. Procesos migratorios y relaciones interétnicas en Andalucía: una reflexión sobre el caso del poniente almeriense desde la antropología social. Madrid: Ministerio de Trabajo y Asuntos Sociales.

Martín Muñoz, Gema (comp.). 1995. Mujeres, democracia y desarrollo en el Magreb. Madrid: Fundación Pablo Iglesias.

Martín Muñoz, Gema. 2012. "La islamofobia inconsciente", en Gema Martín Muñoz y Ramón Grosfoguel (eds.), La islamofobia a debate. La genealogía del miedo al islam y la construcción de discursos antiislámicos: 35-47. Madrid: Casa Árabe.

Martín Sáiz, Guillermo. 2014. «Espacio público e islam transnacional: A propósito de la Jamaat at-Tabligh en Barcelona". Revista de Estudios Internacionales Mediterráneos (REIM) 16. Disponible en: <https:// revistas.uam.es/index.php/reim/article/view/934/922>. Fecha de acceso: 14 may. 2018.

Martínez Antonio, Francisco. 2009. Intimidades de Marruecos. Miradas y reflexiones de médicos españoles sobre la realidad marroqui a finales del siglo XIX. Madrid: Miraguano.

Martínez Veiga, Ubaldo. 1999. Pobreza, segregación y exclusión espacial. La vivienda de los extranjeros en España. Barcelona: Icària.

Martínez Veiga, Ubaldo. 2001. El Ejido, discriminación, exclusión social y racismo. Madrid: Catarata.

Mateo Dieste, Josep Lluis. 2002. «La paraetnografía militar colonial: poder y sistemas de clasificación social", en Ángeles Ramírez y Bernabé López García (coords.), Antropología y antropólogos en Marruecos: homenaje a David M. Hart: 113-133. Barcelona: Bellaterra.

Mateo Dieste, Josep Lluis. 2003. La "hermandad" hispano-marroqui: política y religión bajo el Protectorado español en Marruecos (1912-1956). Barcelona: Bellaterra.

Mateo Dieste, Josep Lluis. 2005. "Amores prohibidos: Fronteras sexuales y uniones mixtas en el Marruecos colonial", en Ana I. Planet y Fernando Ramos López (coords.). Relaciones hispano-marroquies: una vecindad en construcción: 128-161. Madrid: Ediciones del Oriente y del Mediterráneo.

Mateo Dieste, Josep Lluis. 2008. «Sistemas médicos y racionalidades curativas en Marruecos: un panorama general", en Gerardo Fernández Juárez, Irene González Gonzáles y Puerto García Ortiz (coords.), La diversidad ante el espejo: salud, interculturalidad y contexto migratorio: 129-142. Quito: Ediciones Abya-Ayala.

Mateo Dieste, Josep Lluis. 2012. «Una hermandad en tensión. Ideología colonial, barreras e intersección hispano-marroquí en el protectorado". Awraq: Estudios sobre el Mundo Árabe e Islámico Contemporáneo 5-6: 79-96. Disponible en: <http://www.awraq.es/blob.aspx?idx=5\&nId=78\&hash= 4bc6ec3b83a3650311ae459f9f1e11dc>. Fecha de acceso 14 may. 2018.

Mateo Dieste, Josep Lluis. 2013. "Rarezas": conversiones religiosas en el Marruecos colonial (1930-1956)". Hispania: Revista Española de Historia 73(243): 223-252. doi: <https://doi.org/10.3989/ hispania.2013.v73.i243>.

Mateo Dieste, Josep Lluis. 2014. «Una antigua costumbre... Corrupción entre colonizadores y colonizados en Alcázarquivir (1925), protectorado español de Marruecos". Illes i imperis: Estudios de Historia de las Sociedades en el Mundo Colonial y Post-Colonial 16: 147-168.

Mateo Dieste, Josep Lluís. 2017. "Moros vienen". Historia y política de un estereotipo. Melilla: Instituto de las Culturas Ciudad de Melilla.

Mateo Dieste, Josep Lluís y Alexandre Coello de la Rosa. 2016. Elogio de la antropología histórica. Enfoques, métodos y aplicaciones al estudio del poder y del colonialismo. Zaragoza: UOC y Prensas de la Universidad de Zaragoza.

Mijares, Laura. 2006. Aprendiendo a ser marroquíes. Inmigración, diversidad lingüística y escuela. Madrid: Ediciones del Oriente y del Mediterráneo.

Mijares, Laura y Ángeles Ramírez. 2005. "Gestión del islam y de la inmigración en Europa: tres estudios de caso". Migraciones 18: 77-104. Disponible en: <http://revistas.upcomillas.es/index.php/ revistamigraciones/article/view/3046>. Fecha de acceso: 17 may. 2018. 
Mijares, Laura y Ángeles Ramírez. 2008a. "La "islamización" de la inmigración: algunas hipótesis acerca". Quaderns de la Mediterrània 9: 389-392.

Mijares, Laura y Ramírez, Ángeles. 2008b. «Mujeres, pañuelo e islamofobia en España: un estado de la cuestión". Anales de Historia Contemporánea 24: 121-135. Disponible en: <http://revistas.um.es/ analeshc/article/view/53911>. Fecha de acceso: 20 may. 2018.

Mijares, Laura y Johanna M. Lems. 2018. "Luchando contra la subalternidad: las reivindicaciones de la comunidad musulmana de Madrid,, en Laura Mijares, Johanna M. Lems y Virtudes Téllez (coords.), Islamofobia y racismo antimusulmán: un análisis multidisciplinar desde las prácticas: 109-128. Número monográfico de la Revista de Estudios Internacionales Mediterráneos (REIM) 24. doi: <https:// doi.org/10.15366/reim2018.24.007>.

Moga Romero, Vicente. 2009. El Rif de Emilio Blanco Izaga trayectoria militar, arquitectónica y etnografía en el Protectorado de España en Marruecos. Barcelona: Bellaterra.

Montes, Ángel y María José Martínez Martínez. 2011. Diversidad cultural y religion. Minorias religiosas en la region de Murcia. Barcelona: Icaria.

Morales Luque, Lidia y Juan Ignacio Castien Maestro. 2014. "Apuntes sobre la vivencia de la sexualidad entre la juventud marroquí. Investigaciones en Marruecos y en España". Prisma Social. Revista de Ciencias Sociales 13: 491-451. Disponible en: <http://www.isdfundacion.org/publicaciones/revista/ numeros/13/secciones/abierta/a_01_sexualidad_marroqui.html>. Fecha de acceso: 17 may. 2018.

Moreno Navarro, Isidoro. 1975. «La investigación antropológica en España”, en Alfredo Jiménez (coord.), Actas de la I Reunión de Antropólogos Españoles: 325-338. Sevilla: Universidad de Sevilla.

Moreno Nieto, Juana. 2014. "Labour and Gender Relations in Moroccan Strawberry Culture”, en Jörg Gertel y Sarah Ruth Sippel (coords.), Seasonal Workers in Mediterranean Agriculture. The social costs of eating fresh. Londres: Routledge.

Moreno Nieto, Juana. 2017. "Une ethnographie située au nord du Maroc: le rôle du positionnement et des émotions au cours du travail de terrain", en Leila Bouasria, Catherine Therrien y Khalid Mouna (coords.), Terrains marocains. Sur les traces de chercheurs d'ici et d'ailleurs. Rabat/Casablanca: Centre Jacques Berque/Editions de la croiseìe des Chemins

Moreras, Jordi. 1999. Musulmanes en Barcelona: espacios y dinámicas comunitarias. Barcelona: CIDOB.

Moreras, Jordi. 2001a. «Del asentamiento a la integración?: Diez cuestiones en torno al colectivo marroquí en Cataluña". Arxius de Sociología 5: 93-110.

Moreras, Jordi. 2001b. "Temps d'assentament, temps d'integració? El collectiu marroquí a Catalunya", en Salomó Marqués (ed.), Societats pluriculturals i educación: la interculturalitat com a resposta: 105122. Girona: Universitat de Girona.

Moreras, Jordi. 2002a. "Lógicas divergentes, configuración comunitaria e integración social de los colectivos musulmanes en Cataluña", en Francisco Javier de Lucas y Francisco Torres (eds.), Inmigrantes, ¿cómo los tenemos?: algunos desafíos y (malas) respuestas: 196-217. Madrid: Editorial Talasa.

Moreras, Jordi. 2002b. “De la España musulmana al islam español». Vanguardia dossier 1: 85-88.

Moreras, Jordi. 2003a. "Un islam en Cataluña o un islam catalán?", en Maria Angels Roque (coord.), $E l$ islam plural: 335-351. Barcelona: Icaria.

Moreras, Jordi. 2003b. "La inscripción del islam en el espacio público", en Francisco Checa, Juan Carlos Checha y Ángeles Arjona Garrido (coords.), La integración social de los inmigrados: modelos y experiencias: 261-286. Barcelona: Icaria.

Moreras, Jordi. 2003c. "Imágenes del islam en internet", en Carlos Villagrasa (coord.), Nuevas tecnologías de la información y derechos humanos: seminario organizado por la Fundación Internacional Olof Palme: 137-150. Barcelona: Cedecs.

Moreras, Jordi. 2004. «Religions en trànsit. Propostes per a l'anàlisi de les expressions religioses en context migratori.. Revista d'etnologia de Catalunya 24: 44-55. Disponible en: <https://www.raco.cat/index.php/ RevistaEtnologia/article/view/49397/57321>. Fecha de acceso: 20 may. 2018.

Moreras, Jordi. 2005a. «Ravalistán? Islam y configuración comunitaria entre los pakistaníes en Barcelona”. Revista CIDOB d'Afers Internacionals 68: 119-132. Disponible en: <https://dialnet.unirioja.es/servlet/ articulo?codigo=1111695\&orden=182445\&info=link $>$. Fecha de acceso: 20 may. 2018.

Moreras, Jordi. 2005b. «Integrados o interrogados? La integración de los colectivos musulmanes en España en clave de sospecha", en Manuel Hernández Pedreño, Andrés Pedreño (coords.), La condición inmigrante: exploraciones e investigaciones desde la Región de Murcia. Murcia: Universidad de Murcia. 
Moreras, Jordi. 2006a. "Imames en Europa". Afkar ideas 12: 4. Disponible en: <http://www.iemed.org/ observatori/arees-danalisi/arxius-adjunts/afkar/afkar-12/Imames_Europa_Jordi_Moreras_afkar12.pdf>. Fecha de acceso: 20 may. 2018.

Moreras, Jordi. 2006b. Migraciones y pluralismo religioso. Elementos para el debate. Documentos CIDOB, Migraciones 9. Barcelona: CIDOB.

Moreras, Jordi. 2007. Els imams de Catalunya. Barcelona: Editorial Empuriès.

Moreras, Jordi. 2008. "Hoy han hablado en la tele de la mezquita del barrio". Los medios de comunicación en el contexto de los conflictos en torno a los oratorios musulmanes en Cataluña", en María Martínez Lirola (coord.), Inmigración, discurso y medios de comunicación: 127-142. Alicante: Instituto Alicantino de Cultura Juan Gil-Albert.

Moreras, Jordi. 2012. "Imames y radicalización en España”, en Frank Peter y Rafael Ortega (coord.), Los movimientos islámicos transnacionales: y la emergencia de un "islam europeo": 357-360. Barcelona: Bellaterra.

Moreras, Jordi. 2014. "Musalas, mezquitas y minaretes: etnografía de las mezquitas en Europa». Awraq: Estudios sobre el Mundo Árabe e Islámico Contemporáneo 9: 121-146.

Moreras, Jordi. 2015. "Políticas de prevención de la radicalización”. Afkar ideas 45: 30-31. Disponible en: $<$ http://www.iemed.org/observatori/arees-danalisi/arxius-adjunts/afkar/afkar-45/Politicas_prevencion_ radicalizacion_Jordi_Moreras_afkar45es.pdf $>$. Fecha de acceso: 20 may. 2018.

Moreras, Jordi. 2016. "Reconocimiento legal, cuestionamiento del ritual”. Afkar ideas 50: 36-38. Disponible en: <http://www.iemed.org/observatori/arees-danalisi/arxius-adjunts/afkar/afkar-50/Jordi_Moreras_ afkar50.pdf>. Fecha de acceso: 17 may. 2018.

Moreras, Jordi. 2017a. "Las periferias religiosas: allá donde la ciudad pierde (¿̨o recupera?) su fe”, en María Teresa Vicente y Pepa García Hernandorena, Antonio Vizcaíno (coord.), Antropologías en transformación: sentidos, compromisos y utopías: 785-798. Valencia: Universitat de València.

Moreras, Jordi. 2017b. “Contextos imaginados de la radicalización”. Afkar ideas 55: 34-37. Disponible en: $<$ http://www.iemed.org/observatori/arees-danalisi/arxius-adjunts/afkar/afkar-55/ideas_politicas_ contextos_imaginados_radicalizacion_Jordi_Moreras_afkar55.pdf>. Fecha de acceso: 20 may. 2018.

Moreras, Jordi. 2017c. «Qué islam para qué Europa? Hacia una antropología del islam posmigratorio en Europa". Revista CIDOB d'Afers Internacionals 115. doi: <https://doi.org/10.24241/rcai.2017.115.1.13>.

Moreras, Jordi y Sol Tarrés. 2012. "Les cimetières musulmans en Espagne: des lieux de l'alterité. Revue Européenne des Migrations Internationales 28(3): 13-26. Disponible en: <https://journals. openedition.org/remi/5993>. Fecha de acceso: 19 may. 2018.

Observatorio Andalusí. 2018. Estudio demográfico de la población musulmana. Madrid: UCIDE.

Pérez Beltrán, Carmelo. 1997. Mujeres argelinas en lucha por las libertades democráticas. Granada: Universidad de Granada.

Planet, Ana I. 1997. «Asociacionismo e islam: el acuerdo de cooperación del Estado Español con la comisión islámica de España y sus repercusiones en Melilla y Ceuta". Awraq: Estudios sobre el Mundo Árabe e Islámico Contemporáneo 18: 171-194.

Planet, Ana I. 1998. Melilla y Ceuta: espacios-frontera hispano-marroquíes. Melilla: Ciudad Autónoma de Melilla.

Planet, Ana I. 2014. "Spain", en Jocelyne Césari (ed.), The Oxford Handbook of European Islam. Oxford: Oxford University Press. doi: <https://doi.org/10.1093/oxfordhb/9780199607976.001.0001>.

Provansal, Danielle. 1997. "Ritual, cultura y sociedad en el Mediterráneo", en Francisco Checa y Pedro Molina (coords.), La función simbólica de los ritos: rituales y simbolismo en el Mediterráneo: 61-86. Barcelona: Icaria.

Provansal, Danielle. 2002a. "Etnologues "sur le tas" o la etnología de expresión francesa en el Magreb", en Ángeles Ramírez y Bernabé López García (coord.), Antropología y antropólogos en Marruecos: bomenaje a David M. Hart: 171-185. Barcelona: Bellaterra.

Provansal, Danielle. 2002b. "La hospitalidad a prueba: migrantes en Almería", en Francisco Javier García Castaño y Carolina Muriel López (coords.), La inmigración en España: contextos y alternativas: 181193. Granada: Universidad de Granada.

Provansal, Danielle. 2004. "Argelia: ¿Una nación inacabada?". Quaderns de l'Institut Català d'Antropologia 20: 139-155. Disponible en: <https://www.raco.cat/index.php/QuadernsICA/article/view/95590/ 163866>. Fecha de acceso: 15 may. 2018. 
Pumares, Pablo. 1996. La integración de los inmigrantes marroquíes. Familias marroquies en la Comunidad de Madrid. Madrid: Caixa de Pensiones.

Ramírez, Ángeles. 1992. "Marroquíes en España: aproximación a una tipología para el caso del Maresme catalán", en Bernabé López García (coord.), España-Magreb siglo XXI: el porvenir de una vecindad: 249-258. Madrid: Mapfre.

Ramírez, Ángeles. 1993. "La inmigración magrebí en la Cataluña agrícola: marroquíes en el litoral catalán", en Bernabé López García, Mohammed Arkoun, José Cazorla et al., Inmigración magrebí en España: el retorno de los moriscos: 225-240. Madrid: Mapfre.

Ramírez, Ángeles. 1998. Islam, género y migraciones. Mujeres marroquíes en España. Madrid: AECID.

Ramírez, Ángeles. 2011. La trampa del velo: el debate sobre el uso del pañuelo musulmán. Madrid: Catarata.

Ramírez, Ángeles (ed.). 2014. La alteridad imaginada. El pánico moral y la construcción de lo musulmán en España y Francia. Barcelona: Bellaterra.

Ramírez, Ángeles. 2015. "Control over Female "Muslim” Bodies: Culture, Politics and Dress Code Laws in Some Islamic and non Islamic Countries". Identities 22(6): 671-687. doi: <https://doi.org/10.1080/ 1070289X.2014.950972>.

Ramírez, Ángeles. 2016. "La construcción del "problema musulmán”: radicalización, islam y pobreza". Viento Sur 144: 21-30. Disponible en: <http://vientosur.info/spip.php?article11076>. Fecha de acceso: 17 may. 2018.

Ramírez, Ángeles. 2017. "Las otras Soulaliyates: tierra y movilizaciones legítimas e ilegítimas en Marruecos". Revista de Estudios Internacionales Mediterráneos (REIM) 23: 15-28. doi: <https:/doi.org/10.15366/ reim2017.23.002>.

Ramírez, Ángeles y Mercedes G. Jiménez Álvarez (coords.). 2005. Las otras migraciones: la emigración de menores marroquies no acompañados a España. Madrid: Akal.

Ramírez, Ángeles y Bernabé López García (coords.). 2002. Antropología y antropólogos en Marruecos: bomenaje a David M. Hart. Barcelona: Bellaterra.

Ramírez, Ángeles y Laura Mijares. 2018. "Rethinking Re-Islamization: On Muslims and Gender in Spain", en Ana I. Planet Contreras (ed.), Observing Islam in Spain. Contemporary Politics and Social Dynamics: 140-157. Muslim Minorities 28. [s. 1.]: Brill. doi: <https://doi.org/10.1163/9789004364998_004>.

Relaño, Eugenia. 2018. "Existen respuestas jurídicas para la islamofobia?”, en Laura Mijares, Johanna M. Lems y Virtudes Téllez (coords.), Islamofobia y racismo antimusulmán: un análisis multidisciplinar desde las prácticas: 31-48. Número monográfico de la Revista de Estudios Internacionales Mediterráneos (REIM) 24. doi: <https://doi.org/10.15366/reim2018.24.003>.

Ribas, Natalia. 1999. Las presencias de la inmigración femenina: un recorrido por Filipinas, Gambia y Marruecos en Cataluña. Barcelona: Icaria.

Ribas, Natalia. 2001. "Estrategias transnacionales?: una pregunta acerca de las migraciones femeninas en España". Arxius de Sociología 5: 69-92.

Ribas, Natalia. 2005. "Globalización y movimientos migratorios”, en Mercedes G. Jiménez y Ángeles Ramírez (coords.), Las otras migraciones: la emigración de menores marroquíes a España: 27-56. Madrid: Akal.

Rodinson, Maxime. 1980. La fascination de l'islam. París: Maspero.

Roque, Maria Angels (coord.). 2000. Mujer y migración en el Mediterráneo Occidental: tradiciones culturales y ciudadanía. Barcelona: Icaria/Institut Català de la Mediterrània.

Roque, Maria Angels. 2002. "Identidades beréberes marroquíes y redes asociativas campo-ciudad", en Ángeles Ramírez y Bernabé López Fernández (coords.), Antropología y antropólogos en Marruecos: homenaje a David M. Hart: 399-421. Barcelona: Bellaterra.

Roque, Maria Angels. 2006a. "Valores sociales en Marruecos: Entrevista con Mohamed Tozy". Afkar ideas 10: 16. Disponible en: <http://www.iemed.org/observatori/arees-danalisi/arxius-adjunts/afkar/afkarideas-10/Valores_sociales_en_Marruecos._Entrevista_a_Mohamed_Tozy>. Fecha de acceso: 20 may. 2018.

Roque, Maria Angels. 2006b. "La complejidad cultural de Marruecos, una herencia mediterránea: entrevista a Mohamed Tozy". Quaderns de la Mediterrània 6: 105-110.

Roque, Maria Angels. 2009. "La societat civil i la reivindicació amaziga”, en Tassadit Yanzine, Maria Angels Roque, Monsour Ghaki, Mohamed Chafik et al., Els amazics avui, la cultura berber. 141-146. Barcelona: Pagès Editors/IEMed.

Roque, Maria Angels. 2013. "Mujeres en la cultura global". Quaderns de la Mediterrània 18-19: 252-253. Roque, Maria Angels. 2016. "Las mujeres relatan la historia”. Quaderns de la Mediterrrània 23: $289-296$. 
Rosander, Eva Evers. 2004 [1991]. Mujeres en la frontera: tradición e identidad musulmana en Ceuta. Barcelona: Editorial Bellaterra.

Rosón, Javier. 2002. "Muslimofobia vs muslimofilia: comunidades étnicas en la ciudad de Granada", en Francisco Javier García Castaño y Carolina Muriel (coords.), La inmigración en España: contextos y alternativas, vol. 4: 45-53. Granada: Universidad de Granada. Disponible en: <http://digibug.ugr.es/ handle/10481/34474>. Fecha de acceso: 17 may. 2018.

Rosón, Javier. 2008a. "Cultura oral y patrimonio inmaterial en el barrio de Albaycín, Granada: Una aplicación del modelo de catalogación en el marco del proyecto Mediterranean Voices", en Javier Rosón, $E l$ patrimonio cultural inmaterial: definición y sistemas de catalogación: 211-246. Murcia: Universidad de Murcia.

Rosón, Javier. 2008b. «Etnificación de la diversidad religiosa en el barrio de Albayzín", en Mónica Cornejos, Manuela Cantón y Ruy Llera (coords.), Teorías y prácticas emergentes en antropología de la religión: 223-238. San Sebastián: Ankulegi.

Rouse, Carolyn M. 2004. Engaged Surrender: African American Women and Islam. Berkeley: University of California Press. doi: <https://doi.org/10.1111/j.15-48-1425.2008.00057.x>.

Roy, Olivier. 1992. "Les voies de la ré-islamisation". Pouvoirs 62: 81-91.

Roy, Olivier. 2011. "The Paradoxes of the Re-Islamization of Muslim Societies. The Immanent Frame. Secularism, Religion and the Public Sphere". Social Science Research Council 8 sept. Disponible en: $<$ http://blogs.ssrc.org/tif/2011/09/08/the-paradoxes-of-the-re-islamization-of-muslim-societies>. Fecha de acceso: 16 may. 2018.

Ruiz de Almodóvar-Sel, Caridad. 2005. El derecho privado en los países árabes: Códigos de estatuto personal. Granada: Universidad de Granada.

Ruiz Vieytez, Eduardo J. (dir.). 2010. Pluralidades latentes. Minorías religiosas en el País Vasco. Barcelona: Icaria.

Said, Edward W. 2003 [1978]. Orientalism. Londres: Penguin Classics.

Salguero Montaño, Oscar. "A Diachronic View of the Spaces of Islam in Melilla", en Ana I. Planet Contreras (ed.), Observing Islam in Spain. Contemporary Politics and Social Dynamics: 62-84. Muslim Minorities 28. [s. 1.]: Brill. doi: <https://doi.org/10.1163/9789004364998_004>.

Sempere-Souvannavong, Juan David. 1998. Les pieds-noirs en Alicante. Las migraciones de la descolonización. Alicante: Publicaciones de la Universidad de Alicante.

Solana, Vivian. 2017. "Cementing Nationalism: The Role of the Saharawi Revolutionary in her Struggle for Decolonization", en Francisco Freire y Sebastian Boulay (ed.), Culture et politique dans l'Ouest saharien: Arts, Activisme et Etat dans un espace de conflits: 423-444. Igé: Éditions l'Étrave.

Solé, Ariadna. 2012. "Rituals funeraris transnacionals entre Catalunya i Senegal». Revista Catalana de Sociologia 28: 61-69. Disponible en: <http://blogs.iec.cat/acs/2012/12/31/revista-catalana-de-sociologianum-28-2/>. Fecha de acceso: 20 may. 2018.

Solé, Ariadna. 2014. "Ritos funerarios islámicos transnacionales entre Catalunya y Kolda (Senegal). La construcción de la transnacionalidad desde la práctica religiosa y ritual. Revista de Estudios Internacionales Mediterráneos (REIM) 16. Disponible en: <https://revistas.uam.es/index.php/reim/article/view/ 935/3716>. Fecha de acceso: 14 may. 2018.

Solé, Ariadna. 2015. Rituals funeraris islàmics transnacionals. La repatriació de difunts entre Catalunya $i$ Kolda (Senegal). Tesis doctoral. Universitat de Barcelona.

Solé, Ariadna. 2017. "Seguir a los difuntos. Una etnografía multisituada de las prácticas funerarias transnacionales". Revista de Antropología Experimental 17(1): 97-107. Disponible en: <https:// revistaselectronicas.ujaen.es/index.php/rae/article/view/3758/3068>. Fecha de acceso: 20 may. 2018.

Strzelecka, Ewa. 2017. Mujeres en la Primavera Árabe. Construcción de una cultura política de resistencia feminista en Yemen. Madrid: CSIC.

Talha, Larbi, Sossie Andezian, Pierre-Robert Baduel et al. 1983. Maghrébins en France. Emigrés ou immigrés? París: CNRS.

Tarrés, Sol. 2002. "Inmigración magrebí y espacio urbano", en Manuel Luna (coord.), La ciudad en el tercer milenio: 249-268. Murcia: Universidad Católica San Antonio.

Tarrés, Sol. 2003. "Fundamentalismos islámicos, inmigración e identidad: el tablih en Sevilla", en Fernando Amérigo (coord.), Religión, religiones, identidad, identidades, minorias: actas del V Simposio de la Sociedad Española de Ciencias de las Religiones: 373-384. Valencia: Universitat de València. 
Tarrés, Sol. 2005. Inmigrantes extranjeros asentados en Andalucia: Estrategias adaptativas de la comunidad magrebi de Sevilla. Tesis doctoral. Universidad de Sevilla.

Tarrés, Sol. 2006. "Ritos funerarios en el islam: la praxis entre los musulmanes de Sevilla". Zainak: Cuadernos de Antropologia-Etnografía 28: 429-446. Disponible en: <http://www.eusko-ikaskuntza.org/es/ publicaciones/ritos-funerarios-en-el-islam-la-praxis-entre-los-musulmanes-de-sevilla/art-15285/>. Fecha de acceso: 20 may. 2018.

Tarrés, Sol. 2012. "La Yamaat al-Tabligh en España", en Frank Peter y Rafael Ortega (coords.), Los movimientos islámicos transnacionales: y la emergencia de un "islam europeo": 257-261. Barcelona: Bellaterra.

Tarrés, Sol y Celeste Jiménez de Madariaga. 2012. "El pluralismo religioso en Andalucía", en Celeste Jiménez de Madariaga y José Hurtado (coords.), Andalucía. Identidades culturales y dinámicas sociales: 261286. Andalucía: Centro de Estudios Andaluces/Junta de Andalucía/Asana.

Tarrés, Sol y Javier Rosón. 2009. "La enseñanza de las religiones minoritarias en la escuela: análisis del caso de Andalucía". Revista de Ciencias de las Religiones 14: 179-197. Disponible en: <http:// revistas.ucm.es/index.php/ILUR/article/view/ILUR0909110179A/25685>. Fecha de acceso: 20 may. 2018.

Tarrés, Sol y Javier Rosón. 2014a. "Los orígenes de la institucionalización del islam en Espña: bases y fundamentos (1900-1992)". Awraq: Estudios sobre el Mundo Árabe e Islámico Contemporáneo 9: 147-170. Disponible en: $<$ http://www.awraq.es/blob.aspx?idx=5\&nId=110\&hash=2b9e551371fe9fe37bcbc5d2e08e4d22>. Fecha de acceso: 20 may. 2018.

Tarrés, Sol y Javier Rosón. 2014b. «Estado y confesiones religiosas minoritarias: representaciones, diálogos y controversias del islam en España (1936-1992)", en José Miguel Delgado Idarreta, Rebeca Viguera y Julio Pérez Serrano (coords.), Iglesia y Estado en la sociedad actual: política, cine y religión: 169182. La Rioja: Instituto de Estudios Riojanos.

Tarrés, Sol y Javier Rosón. 2017. “¿Musulmanes o inmigrantes? La institucionalización del islam en España (1860-1992)". Revista CIDOB d'Afers Internacionals 115: 13-37. doi: <https://doi.org/10.24241/ rcai.2017.115.1.13>.

Tarrés, Sol y Jordi Moreras. 2017. "Patrimonio cultural funerario. Los cementerios de las minorías religiosas en España", en Beatriz Santamarina (coord.), Geopolíticas patrimoniales: de culturas, naturalezas e inmaterialidades. Una mirada: 267-283. Valencia: Editorial Neopatria.

Téllez, Virtudes. 2008. "La juventud musulmana de Madrid responde: lugar y participación social de las asociaciones socioculturales formadas o revitalizadas después de los atentados del 11-M". Revista de Estudios Internacionales Mediterráneos (REIM) 6: 133-143. Disponible en: <https://revistas.uam.es/ index.php/reim/article/view/790>. Fecha de acceso: 20 may. 2018.

Téllez, Virtudes. 2009. "Identificaciones personales y su potencial de integración en la cultura civil", en Matilde Fernández Montes y Traude Müllauer-Seichter (coords.), La integración escolar a debate: 3955. Madrid: Pearson.

Téllez, Virtudes. 2010. «La crisis como génesis. Ser hoy joven musulmán en Madrid», en María García Navarro, Betty Estévez y Antolín Sánchez (eds.), Claves actuales de pensamiento. Seminario Internacional de Jóvenes Investigadores: 107-120. Madrid: Plaza y Valdés.

Téllez, Virtudes. 2011a. Contra el estigma: jóvenes españoles/as y marroquies transitando entre la ciudadanía y la "musulmaneidad. Tesis doctoral. Universidad Autónoma de Madrid.

Téllez, Virtudes. 2011b. "Respuesta de los musulmanes a los atentados del 11 de marzo", en Cristina SánchezCarretero (coord.). El Archivo del Duelo: Análisis de la respuesta ciudadana ante los atentados del 11 de marzo en Madrid: 157-170. Madrid: CSIC.

Téllez, Virtudes. 2014a. "La sospecha y los vínculos transnacionales como cuestionamiento de la identificación civil de musulmanes españoles jóvenes en Madrid”. Revista de Estudios Internacionales del Mediterráneo (REIM) 16. Disponible en: <https://revistas.uam.es/index.php/reim/article/view/930/ 3713>. Fecha de acceso: 14 may. 2018.

Téllez, Virtudes. 2014b. “Somos "ciudadanos musulmanes españoles”: posibilidades de conciliar la ciudadanía española y la religiosidad islámica", en Ángeles Ramírez (ed.), La alteridad imaginada: El pánico moral y la construcción de lo musulmán en España y Francia: 219-242. Barcelona: Bellaterra.

Téllez, Virtudes. 2017. «Emboding Religiosities and Subjectivities: The Responses of Young Spanish Muslims to Violence and Terrorism in the Name of Islam", en José Mapril, Ruy Blanes, Emerson Giumbelli y Erin K. Wilson (eds.), Secularism in a Postsecular Age? Religiosities and Subjectivities in Comparative Perspective: 87-106. Cham: Palgrave MacMillan. doi: <https://doi.org/10.1007/978-3-319-43726-2>. 
Téllez, Virtudes. 2018. «El "Pacto Antiyihadista” y sus implicaciones jurídicas, políticas y sociales: un análisis desde los debates parlamentarios", en Johanna M. Lems, Laura Mijares y Virtudes Téllez (coords.), Islamofobia y racismo antimusulmán: un análisis multidisciplinar desde las prácticas. Número monográfico de la Revista de Estudios Internacionales Mediterráneos (REIM) 24: 9-30. doi: <https:// dx.doi.org/10.15366/reim2018.24.002>.

Tello Weiss, Mariana. 2007. El otro entre nosotros. Una aproximación antropológica a las construcciones sobre el "terrorismo islamista" en la prensa tras el 11-M. Tesis para la obtención del Diploma de Estudios Avanzados. Universidad Autónoma de Madrid.

Urrutia, Gorka (dir.). 2017. Entrelazados. Minorías religiosas en Asturias, Cantabria y La Rioja. Barcelona: Icaria.

Valero, Jesús A. (dir.). 2012. Hablando de lo religioso. Minorías religiosas en Castilla y León. Barcelona: Icaria.

Varisco, Daniel M. 2005. Islam Obscured. The Rethoric of Anthropological Representation. Nueva York: Palgrave Macmillan. doi: <https://doi.org/10.1057/9781403973429>.

Zapata, Javier. 1993. "Aspectos de la situación legal de los magrebíes en la comarca de L'Horta (Valencia)", en Bernabé López García (ed.), Inmigración magrebi en España. El retorno de los moriscos: 253266. Madrid: Mapfre.

Zapata Barrero, Ricard. 2006. "The Muslim Community and Spanish Traditon: Maurophobia as a Fact and Impartiality as a Desideratum", en Tariq Modood, Anna Triandafyllidou y Ricard Zapata (eds.), Multiculturalism, Muslims and Citizenship: A European Approach: 143-161. Londres: Routledge.

Zine, Yasmine. 2006. "Unveiled Sentiments: Gendered Islamophobia and Experiences of Veiling among Muslim Girls". Canadian Islamic School, Equity E Excellence in Education 39(3): 239-252. doi: <https:/ /doi.org/10.1080/10665680600788503>.

Fecha de recepción: 21 de mayo de 2018

Fecha de aceptación: 25 de junio de 2018 